\title{
Propriedades eletrônicas e estruturais de fluidos supercríticos. Avaliação de campos de força para descrição do espectro de absorção da paranitroanilina em $\mathrm{CO}_{2}$ supercrítico.
}

\author{
Ricardo de Lima
}

Orientador: Prof. Sylvio Roberto Accioly Canuto

Dissertação apresentada ao Instituto de Física da Universidade de São Paulo para a obtenção do título de Mestre em Ciências.

Banca Examinadora:

Prof. Sylvio Roberto Accioly Canuto (IFUSP)

Prof. Antonio Carlos Borin (IQ/USP)

Prof. Herbert de Castro Georg (UFG) 
FICHA CATALOGRÁFICA

Preparada pelo Serviço de Biblioteca e Informação do Instituto de Física da Universidade de São Paulo

Lima, Ricardo de

Propriedades eletrônicas e estruturais de fluidos supercríticos. Avaliação de campos de força para descrição do espectro de absorção da paranitroanilina em CO2 supercrítico. - São Paulo, 2016.

Dissertação (Mestrado) - Universidade de São Paulo. Instituto de Física - Depto. de Física Geral.

Orientador: Prof. Dr. Sylvio Roberto Accioly Canuto

Área de Concentração: Física

Unitermos: 1. Solvatação; 2. Absorção; 3. Estrutura Eletrônica; 4. Fluidos Supercríticos.

USP/IF/SBI-068/2016 
"Para ser grande, sê inteiro: nada

Teu exagera ou exclui.

Sê todo em cada coisa. Põe quanto és No mínimo que fazes.

Assim em cada lago a lua toda Brilha, porque alta vive".

Odes de Ricardo Reis (14/2/1933) 



\section{Agradecimentos}

Sylvio, não tem nem como agradecer a oportunidade de participar do grupo. Muito obrigado pela paciência, conselhos e ensinamentos durante todo este trabalho. Agradeço muito a oportunidade que me foi dada. Tudo isso me proporcionou muito crescimento pessoal e profissional.

Agradeço muito a todo o pessoal do grupo de física atômica e molecular do IFUSP e a Professora Kaline, em especial. Muito obrigado mesmo.

Aos amigos Fernando, Evanildo e Tárcius pela grande ajuda e atenção que me foi dada para o desenvolvimento deste trabalho.

Agradeço aos meus pais, pela força e perseverança que me deram durante todo o percurso.

À Vivian por sempre estar ao meu lado.

E ao pessoal do meu trabalho, pela compreensão pelas faltas e momentos de ausência.

Sylvio, muito obrigado. 


\section{RESUMO}

Neste trabalho estudamos as propriedades estruturais e eletrônicas do $\mathrm{CO}_{2}$ supercrítico, iniciando com a avaliação de campos de força balizados por aplicações anteriores de simulação quântica do tipo Dinâmica Molecular de Born-Oppenheimer (BOMD). A aplicação principal é a descrição do espectro de absorção da paranitroani-

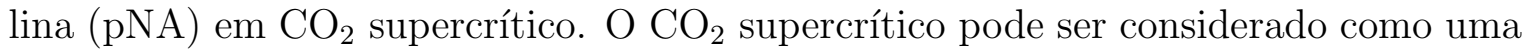
"alternativa verde" para os solventes orgânicos convencionais e a busca por solventes mais seguros, juntamente com a crescente consciência sobre a questão ambiental, tem levado a uma "química verde" com o intuito de se buscar soluções sustentáveis. A princípio estudamos três campos de força tradicionais para o $\mathrm{CO}_{2}$, aplicados na região supercrítica. Estes campos de força podem ser validados por meio de simulação de primeiros principios. Iniciamos considerando a condição supercrítica para o $\mathrm{CO}_{2}$ como $T=315 K, \rho=0.81 \mathrm{~g} / \mathrm{cm}^{3}$ e o campo de força clássico de Zhang e Duan. Depois fizemos uma análise consistindo de uma alteração de cargas e também da geometria do $\mathrm{CO}_{2}$, que seria um caso não linear no qual foi considerado um ângulo $\theta_{O-C-O}=176^{\circ}$. O estudo do solvatocromismo da pNA em $\mathrm{CO}_{2}$ supercrítico foi feito considerando todas estas situações descritas para o campo de força, avaliando os resultados experimentais e teóricos já existentes. A simulação gera estruturas usando Monte Carlo e são usadas em cálculos de Mecânica Quântica do tipo DFT (CAM-B3LYP). Por fim, para verificar a importância da geometria do sistema, ou seja, a propriedade estrutural, consideramos uma outra geometria para a pNA, diferente da geometria que utilizamos a princípio nas simulações com o $\mathrm{CO}_{2}$ supercrítico. Essa "geometria modificada" da pNA foi obtida de uma simulação existente de Born-Oppenheimer e a utilizamos numa simulação Monte Carlo com o caso não linear para o $\mathrm{CO}_{2}$ supercrítico. Os resultados de todas essas simulações nos indicaram que a alteração das cargas e por consequência 
a alteração da polarização do solvente, não possui muita importância na mudança do espectro de absorção da pNA. Ao se considerar o $\mathrm{CO}_{2}$ não linear, obtivemos resultados um pouco melhor, mas não muito, comparados com a previsão teórica. Mas os resultados mais significativos são os obtidos para a situação em que utilizamos a geometria modificada da pNA. Uma parte do deslocamento do máximo da banda de absorção no espectro da pNA vem com a contribuição eletrostática da interação soluto-solvente e a outra parte vem da mudança estrutural.

Palavras chave: S-QM/MM, solvatocromismo, espectro de absorção, fluidos supercríticos. 


\section{ABSTRACT}

In this work we study the structural and electronic properties of $\mathrm{CO}_{2}$ supercritical starting with the evaluation of force fields based on previous ab initio BornOppenheimer molecular dynamics (BOMD). The main application is the description of the absorption spectrum of paranitroanilina (pNA) in supercritical $\mathrm{CO}_{2}$. The supercritical $\mathrm{CO}_{2}$ is considered a "green alternative" to conventional organic solvents and the search for safer solvents, along with the increasing awareness of environmental issues has led to the interest in "green chemistry", seeking sustainable solutions. At first we studied three traditional force fields for $\mathrm{CO}_{2}$, applied in the supercritical region. These force fields can be validated by first principles simulation. We considered the supercritical condition for $\mathrm{CO}_{2}$ as $T=315 \mathrm{~K}, \rho=0.81 \mathrm{~g} / \mathrm{cm}^{3}$ and the classical force field of Zhang and Duan. We also did an analysis consisting of a change of the atomic point charges and the geometry of $\mathrm{CO}_{2}$, including a non-linear case in which an angle $\theta_{O-C-O}=176^{\circ}$ was considered. The study of the solvatochromism of pNA in supercritical $\mathrm{CO}_{2}$ was made considering all these situations, evaluating the theoretical outcome and the experimental results. The simulation generates structures using Monte Carlo and are used in quantum mechanics calculations of DFT (CAM-B3LYP). To verify the importance of geometry in the system, that is, the structural property, we considered another geometry for the pNA geometry different from that we used initially in the simulations with supercritical $\mathrm{CO}_{2}$. This "modified geometry" of pNA was obtained from a previous Born-Oppenheimer simulation and was used in a Monte Carlo simulation with the non-linear case for supercritical $\mathrm{CO}_{2}$. The results of all these simulations indicated that the alterations of charge and thus the change in the polarization of the solvent, has no great importance in the change of the absorption spectrum of the pNA. When considering the nonlinear $\mathrm{CO}_{2}$, we obtained slightly bet- 
ter results. But the most significant results are obtained for the situation in which we use the modified geometry of pNA. Part of the shift in the absorption spectrum of the pNA comes with the electrostatic contribution of solute-solvent interaction and the other part comes from the structural change.

Keywords: S-QM/MM, solvatochromism, absorption spectrum, supercritical fluids. 


\section{LISTA DE ABREVIAÇÕES}

ASEC

Average Solvent Electrostatic Configuration

B3LYP

Funcional de densidade híbrido

BOMD

Dinâmica Molecular de Born-Oppenheimer

$\mathrm{BO}$

Aproximação de Born-Oppenheimer

CAM-B3LYP Funcional de densidade híbrido com correção de longo alcance

DFT

Teoria do Funcional da Densidade

$\mathrm{HF}$

Método de Hartree-Fock

$\mathrm{HOMO}$

Orbital Molecular ocupado mais alto

LCAO

Combinação Linear de Orbitais Atômicos

LDA

Aproximação Local da Densidade

LSDA

Aproximação Local da Densidade de Spin

LUMO

Orbital Molecular não ocupado mais baixo

$\mathrm{MC}$

Monte Carlo

MDDF

Função de Distribuição de Mínima Distância

$\mathrm{MM}$

Mecânica Molecular

PCM

Modelo Contínuo Polarizável

pNA

Paranitroanilina

$\mathrm{QM}$

Mecânica Quântica

$\mathrm{QM} / \mathrm{MM}$

Mecânica Quântica / Mecânica Molecular

$\mathrm{RDF}$

Função de Distribuição Radial

SCF

Fluidos Supercríticos

SCRF

Campo de Reação Autoconsistente

S-QM/MM

Sequencial - Mecânica Quântica / Mecânica Molecular

TDFT

Teoria do Funcional da Densidade Dependente do Tempo 


\section{Índice}

1 Introdução 1

2 Simulação Computacional de Líquidos e o Método Sequencial QM/MM 7

2.1 Os Modelos Contínuos . . . . . . . . . . . . . . . 7

2.2 O Método Sequencial QM/MM . . . . . . . . . . . . . . 10

2.3 A Simulação Computacional . . . . . . . . . . . . . . . . . . . 13

2.4 O Método Monte Carlo . . . . . . . . . . . . . . . . 15

2.5 O Potencial Interatômico . . . . . . . . . . . . . . . . . . 17

2.6 A Função de Distribuição Radial de Pares G(r) e a Autocorrelação da Energia . . . . . . . . . . . . . . . . . . . . 19

2.6.1 A Função de Distribuição de Pares G(r) . . . . . . . . . . . . 19

2.6.2 Autocorrelação da Energia . . . . . . . . . . . . . . . . . . . 22

3 Métodos Quânticos de estrutura eletrônica 23

3.1 A Aproximação de Born-Oppenheimer . . . . . . . . . . . . . . . . 24

3.2 Método de Hartree-Fock . . . . . . . . . . . . . . . . . . . 27

3.3 Teoria de Perturbação de Møller Plesset . . . . . . . . . . . . . . . . . 29

3.4 Teoria do Funcional da Densidade . . . . . . . . . . . . . . . . . . 31

3.5 O funcional híbrido CAM-B3LYP . . . . . . . . . . . . . . . . 34 
4 Resultados $\quad 39$

4.1 Análise dos potenciais clássicos . . . . . . . . . . . . . . . . . . . . . 39

4.2 A estrutura da pNA em Fluido Supercrítico $\mathrm{CO}_{2} \quad \ldots \ldots$. . . . . . . . 45

4.3 O Espectro de absorção da pNA em Fluido Supercrítico $\mathrm{CO}_{2}$.... 49

4.3.1 Simulação clássica de MC da pNA em Fluido Supercrítico $\mathrm{CO}_{2}$. 49

4.3.2 Cálculo do espectro eletrônico . . . . . . . . . . . . . . . . . 51

5 Conclusões e Perspectivas $\quad 59$

$\begin{array}{ll}\text { Referências Bibliográficas } & 63\end{array}$ 


\section{Introdução}

Neste capitulo iremos apresentar o problema considerado neste trabalho e as motivações para estudá-lo. Os métodos quânticos, utilizados para se buscar uma solução aproximada para a equação de Schroedinger, também serão brevemente mencionados. Iremos abordar a questão de fluidos supercríticos e ao final, discutiremos o objetivo deste trabalho.

A estrutura eletrônica de átomos, moléculas e sólidos pode ser obtida pela solução da equação de Schroedinger independente do tempo. Ao longo de quase noventa anos ela tem sido usada para desvendar as mais importantes propriedades destes sistemas. O seu sucesso é inegável e o desenvolvimento, desde os pioneiros até recentemente, tem sido na parte de métodos, algoritmos e recursos computacionais. Isto se deve às conhecidas dificuldades matemáticas e numéricas para a solução aproximada da equação de Schroedinger para sistemas de interesse.

São vários os pesquisadores que foram laureados com o Prêmio Nobel, como consequência de seus avanços tanto conceituais como metodológicos. É possível dizer, como ousou Dirac anos atrás, que a maior dificuldade seria de origem computacional. Infelizmente, este aspecto é colocado em questão quando se considera o estudo de sistemas em fase líquida. Como se sabe, a equação de Schroedinger é a mesma, não exibindo qualquer dependência com uma condição termodinâmica. Por ser independente destas condições ela deve ser suplementada com a mecânica estatística para 
estudos da estrutura eletrônica de sistemas em fase líquida. A incursão do poderoso ferramental da Física necessita de ingredientes extras além da mecânica quântica da equação de Schroedinger, seja em sua forma estacionária ou dependente do tempo.

A utilização de métodos combinados de mecânica quântica (QM) e mecânica clássica ou mecânica molecular (MM) é a base dos métodos híbridos chamados abreviadamente de QM/MM [1]. No uso de MM é incorporada a condição termodinâmica. Em nosso grupo, geralmente, usamos a simulação de Monte Carlo Metropolis [2], que é feita em um ensemble, seja NVT ou NPT, de acordo com a conveniência do problema. Estas configurações geradas são submetidas posteriormente aos cálculos de QM, levando então às propriedades do sistema como grandezas estatísticas. A ideia do método QM/MM aparece em artigo de Warshell e Levitt [3] e levou-os ao prêmio Nobel de Química de 2013. Neste artigo eles apresentaram pela primeira vez uma reação enzimática usando mecânica quântica. A partição foi que QM foi usado no sítio ativo da enzima e a MM nos amino-ácidos distantes deste sítio. É aceitável que amino-ácidos distantes do sítio reativo tenham uma participação secundária e, assim, sua estrutura eletrônica poderia ser secundária. Em nossa metodologia, desenvolvida desde alguns anos atrás e em constante desenvolvimento [4], estamos interessados em sistemas em fase líquida e, portanto preferimos um tratamento sequencial. A parte MM gera a estrutura do líquido na condição termodinâmica desejada e, posteriormente, cálculos de QM são realizados em estruturas selecionadas. A seleção é feita tendo-se em conta a correlação estatística entre as configurações geradas na simulação. A correlação estatística, por sua vez, é obtida calculando-se a função de auto-correlação da energia [4] e este procedimento tem sido muito usado para estudar espectroscopia de sistemas atômicos e moleculares em um meio líquido. Dentre as espectroscopias, há aplicações das mais diferentes como infra-vermelho, Raman, NMR, dicroísmo circular, absorção de 2 fótons, etc. 
Com a metodologia sequencial QM/MM estamos definitivamente na área de estrutura eletrônica de líquidos. Uma parte importante computacionalmente é que a simulação é feita de forma clássica (ou Monte Carlo ou Dinâmica Molecular) com o uso de parâmetros estabelecidos a priori. Por exemplo, para líquidos é comum o uso de potenciais do tipo 6-12 Lennard-Jones com parâmetros já obtidos anteriormente. É importante ressaltar, neste momento, que muitas das simulações MM são assim feitas com campo de força parametrizados e que se mostraram robustos em diversas aplicações. Entretanto, em outros casos mais complexos, foi necessário ir além da simulação clássica com campos de força parametrizados e realizar simulações quânticas de dinâmica molecular [5].

Uma questão a ser considerada agora é a possibilidade de avançar no diagrama de fases, entretanto na região bem mais complexa dos fluidos supercríticos. Mostramos na figura 1.1 um diagrama de fases ilustrativo, que não se refere a nenhum sistema em particular. Ao final da linha de coexistência entre as fases líquido e gás tem-se o ponto crítico. Assim, o ponto crítico (caracterizado por uma temperatura $T_{c}$ e uma pressão $P_{c}$ e que tem associado uma densidade $\rho_{c}$ ) é o ponto de convergência entre a crescente densidade do gás e a decrescente densidade do líquido. Como é de esperar, trata-se de um ponto que exibe singularidades e enormes flutuações.

Além deste ponto está a região de fluidos supercríticos (SCF). Esta é uma região de grande interesse na Física (na mecânica estatística de fenômenos críticos, em particular) mas também na Química e no setor industrial.

Os fluidos supercríticos apresentam enorme flexibilidade físico-química. A título de exemplo, dependendo do ponto $(T, P)$, a água na região supercrítica [6] [7] [8] tem sua constante dielétrica $\epsilon$ variando de 2 a 30, comparado com a situação termodinâmica normal onde ela vale aproximadamente 80. Assim, a água na região supercrítica tem características que mudam de um valor associado a hexano $(\epsilon=1,8)$ até um solvente 


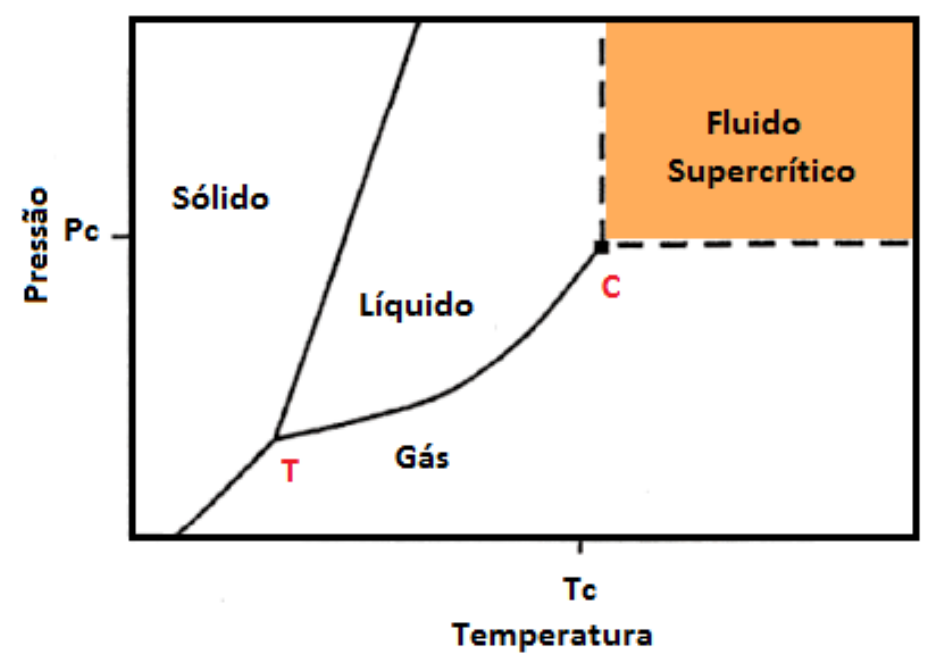

Figura 1.1: Diagrama de fases de um sistema arbitrário que ilustra o ponto crítico (C) e a região de fluido supercrítico.

de alta polaridade como é o caso do álcool metanol $(\epsilon=32,6)$. Desta maneira, a constante dielétrica da água possui uma dependência com as condições termodinâmicas [9] [10]. Esta diversidade permite o controle da solubilidade e reatividade molecular do meio. São estas características que fazem os fluidos supercríticos de grande interesse industrial e estarem associados ao que se chama de química verde [61] [62] (por utilizar solventes não danosos). Embora, como regra geral, a água é o fluido de maior interesse no caso supercrítico, além da água o $\mathrm{CO}_{2}$ é de enorme interesse, por apresentar um baixo custo, ser não tóxico, não inflamável e de fácil obtenção e reciclagem. Um outro ponto importante decorre de sua temperatura crítica ser bastante baixa $\left(T_{c}=304.1 \mathrm{~K}\right)$ e acessível na prática. Mas por outro lado, existem também questões fundamentais associadas ao $\mathrm{CO}_{2}$ supercrítico. É motivo de discussões se numa região supercrítica ele teria um comportamento de um fluido polar, mudando suas características de solvente apolar para solvente polar, o que acarretaria mudanças importantes nas forças intermoleculares do fluido. Estas questões são de interesse neste trabalho e iremos estudar o espectro de absorção da paranitroanilina (pNA) em fluido supercrítico, sendo 
utilizado o $\mathrm{CO}_{2}$ supercrítico como solvente.

Inicialmente verificamos e validamos campos de força tradicionais para o $\mathrm{CO}_{2}$, que foram aplicados na região supercrítica. Isso foi feito considerando-se 3 tipos de campos de força, que diferem entre si com relação as cargas e geometria considerada. Em um dos casos, utilizamos uma geometria não linear para o $\mathrm{CO}_{2}$ supercrítico [5].

Após validados estes campos de força, numa segunda etapa fizemos simulações clássicas de Monte Carlo (MC) entre a pNA e cada um destes casos para o $\mathrm{CO}_{2}$ supercrítico. Ao comparar estas simulações, buscamos com isso analisar alguns pontos importantes, tais como a contribuição eletrostática e influências da geometria do sistema. Propusemos também um último caso, no qual alteramos a geometria da pNA [72]. Por fim, fizemos um estudo do solvatocromismo da pNA em $\mathrm{CO}_{2}$ supercrítico, por meio de cálculos quânticos para obtenção do espectro eletrônico de absorção da pNA neste meio solvente e comparamos com os valores experimentais já existentes, sendo que a alteração da geometria da pNA teve uma influência importante nos resultados obtidos.

Como o resultado obtido anteriormente na referência [12] indicava a inviabilidade de alguns campos de força por não reproduzirem o que se chama de $\mathrm{CO}_{2}$-filicidade, ou seja, a capacidade da pNA de atrair $\mathrm{CO}_{2}$ através de uma interação intermolecular não convencional [13], nosso objetivo consiste em verificar alternativas para um campo de força deste sistema pNA $+\mathrm{CO}_{2}$ supercrítico, onde apenas através de simulações clássicas e cálculos quânticos (S-QM/MM), possamos obter resultados em concordância com os dados experimentais já existentes, sem que ocorra a necessidade de usar uma dinâmica molecular de Born-Oppenheimer, cujo custo computacional se torna elevado por se tratar de simulações de primeiros princípios ou cálculos ab initio. 


\section{Simulação Computacional de Líquidos e o Método Sequencial $\mathrm{QM} / \mathrm{MM}$}

Neste capítulo iremos falar brevemente de alguns pontos principais sobre simulação computacional de líquidos. Serão abordados tópicos como modelos de solvente contínuo e discreto e também os métodos híbridos $Q M / M M$ e $S$-QM/MM e suas vantagens e desvantagens. O Método de Monte Carlo será discutido e alguns conceitos como potencial interatômico, função de distribuição radial de pares e autocorrelação de energia também serão vistos.

\subsection{Os Modelos Contínuos}

Existem vários textos como referência para este assunto [14] [15] [16]. Irei pontuar os aspectos que foram mais importantes para a conclusão deste trabalho.

A maioria das reações químicas importantes acontecem em solução e para se representar significativamente um sistema líquido, é preciso um grande número de moléculas. Isto torna difícil o tratamento do sistema, devido as limitações computacionais. Para tornar possível um estudo de um sistema molecular desta forma, foi necessário o desenvolvimento de métodos e técnicas que reduzissem o número de cálculos. Estes métodos de mecânica quântica foram criados com o objetivo de se estudar as alterações em propriedades de moléculas devido aos efeitos causados pelo solvente. 
Um outro ponto difícil que deve ser levado em conta, é que num líquido não podemos desprezar as interações entre as moléculas, já que elas não estão afastadas o bastante. Porém não estão próximas o suficiente como na fase sólida, o que poderia gerar algumas simetrias. Tudo isso torna difícil desenvolver uma teoria microscópica da fase líquida, pois um líquido é um sistema denso e desordenado.

Diversas propriedades moleculares se modificam dependendo de qual meio a molécula se encontra. Como um exemplo, podemos falar do solvatocromismo [17], que é a diferença de energia de absorção de uma molécula em diferentes ambientes químicos. Uma modelagem teórica desse fenômeno se torna interessante, pois grande parte dos resultados experimentais de espectros de absorção são medidos em solução.

Podemos citar como um primeiro tratamento das interações de moléculas com o meio solvente, o método de campo de reação autoconsistente (SCRF) [18]. Este método considera o solvente como um meio contínuo (uniforme) e polarizável de constante dielétrica $\varepsilon$.

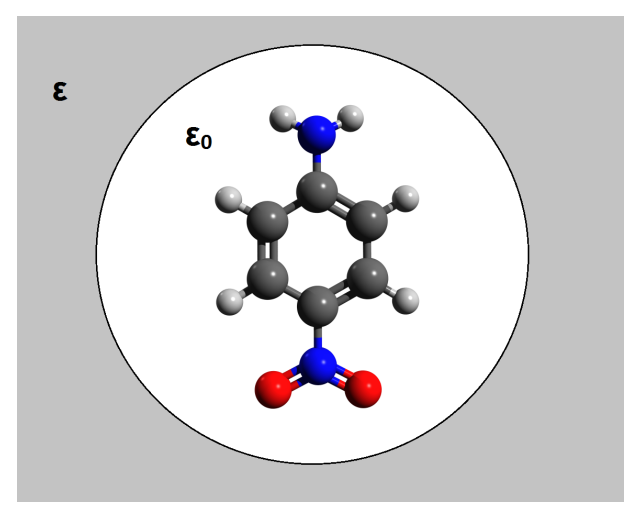

Figura 2.1: Modelo Contínuo - SCRF, no qual a molécula é colocada numa cavidade enquanto que o solvente é representado de forma contínua com constante dielétrica $\varepsilon$. Figura baseada na referência [15].

Esse meio possui uma cavidade genérica onde se encontra a molécula do soluto [19]. A ideia é simples. O soluto possui uma certa distribuição de cargas $\varepsilon_{0}$ e isto polariza 
o meio, ou seja, acarreta uma mudança dos momentos eletrostáticos. Como resposta, o meio age de volta sobre o soluto. Esse processo ocorre sucessivamente, gerando uma autoconsistência. A cavidade pode ter diferentes formas, por exemplo, esférica ou elipsoidal.

Outros modelos surgiram, com o propósito de representar o solvente de forma mais real e um destes modelos é o Modelo Contínuo Polarizável (PCM) [20] [21] [22]. No PCM a cavidade deixou de ser esférica e agora é formada pela união de esferas centradas nos átomos da molécula. O raio destas esferas é em torno de $20 \%$ maior que o raio de Van der Waals do respectivo átomo e isto gera uma superfície que possui a mesma forma da molécula. No PCM o soluto gera uma densidade superficial de cargas na superfície da cavidade e com isto temos um melhor tratamento para a interação eletrostática com o meio solvente.

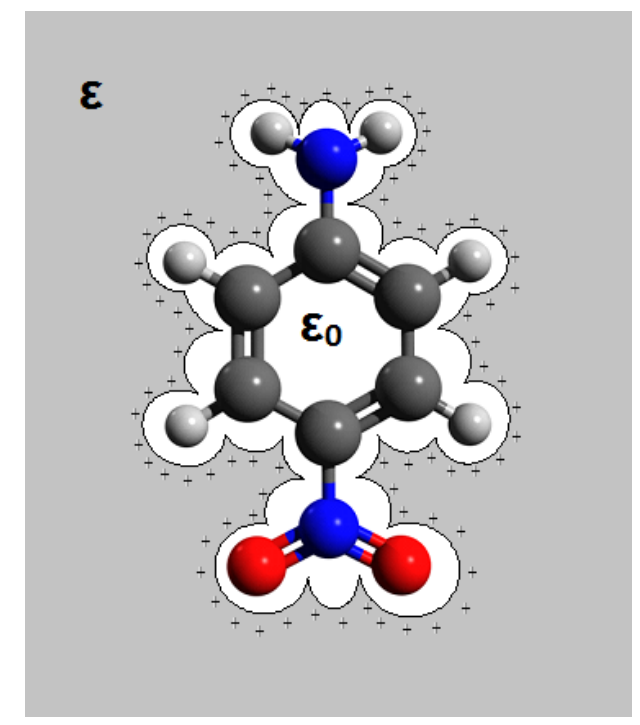

Figura 2.2: Modelo Contínuo Polarizável - PCM. Figura baseada na referência [15].

Embora o PCM descreva bem as interações eletrostáticas para moléculas com grande momento de dipolo, já não descreve tão bem sistemas com interações específicas como 


\section{Simulação Computacional de Líquidos e o Método Sequencial QM/MM}

ligações de hidrogênio. Como não há elétrons no solvente, a transferência de carga do soluto para o solvente, e vice-versa, também não pode ser considerada no PCM.

Vemos então que nos modelos de solvente contínuo o líquido não tem estrutura, ou seja, não existem moléculas que constituem o líquido e este é tratado apenas como um dielétrico contínuo [20]. Nestes modelos não são consideradas as interações intermoleculares explícitas, como as ligações de hidrogênio entre o soluto e solvente por exemplo. Todos esses modelos são baseados na equação de Poisson, relacionando a distribuição de cargas $\rho$, o potencial eletrostático $\phi$ e a constante dielétrica $\varepsilon$ :

$$
\nabla^{2} \phi(r)=-\frac{4 \pi \rho(r)}{\varepsilon}
$$

Nos modelos discretos de solvente, o líquido é constituído por moléculas explícitas. As interações intermoleculares passam a ser aproximadas por um potencial interatômico. Como uma aplicação destes modelos discretos podemos citar dois métodos de simulação computacional, a Dinâmica Molecular e o Método de Monte Carlo.

Os métodos híbridos QM/MM e S-QM/MM, que serão discutidos a seguir, tem como proposta aplicar a simulação clássica juntamente com cálculos de mecânica quânticos.

\subsection{O Método Sequencial QM/MM}

Os métodos híbridos combinam cálculos quânticos e simulações clássicas. São conhecidos pela sigla QM/MM: Quantum Mechanics/Molecular Mechanics [23] [24] e também S-QM/MM: Sequential-Quantum Mechanics/Molecular Mechanics, que foi o método desenvolvido por Canuto e Coutinho [25] [26].

No método QM/MM é escolhida uma pequena parte do sistema que será tratada quanticamente e o restante é tratado com campos de força empíricos. A questão está em como escolher a parte que deve ser tratada com Mecânica Quântica. Po- 
deríamos, por exemplo, considerar apenas a primeira camada de solvatação, ou então as moléculas do solvente que fazem pontes de hidrogênio com o soluto, de modo que isso fosse capaz de calcular uma certa propriedade de uma molécula.

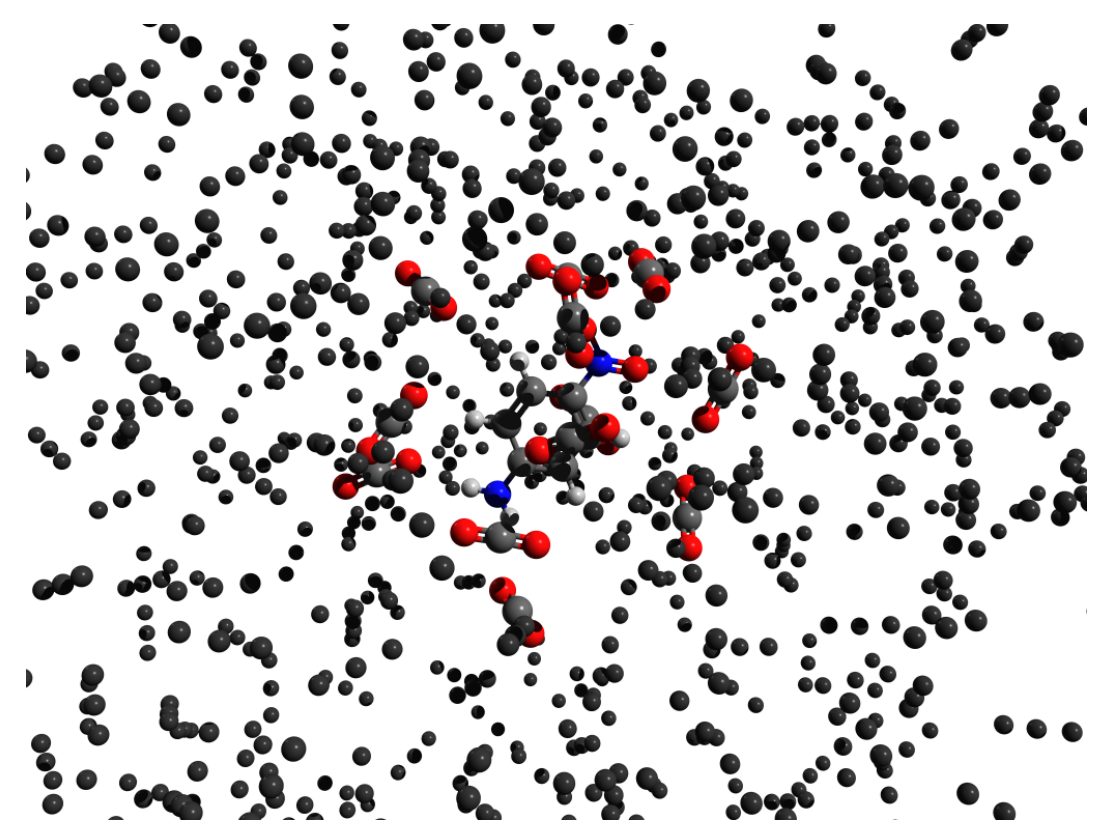

Figura 2.3: No método QM/MM, as moléculas centrais são tratadas com Mecânica Quântica, porém as demais (pontos em cinza) são tratadas classicamente.

Depois disto, torna-se necessário pensar em como acoplar as interações da parte clássica e quântica e isto é um tratamento que define os vários métodos de QM/MM. Além disto os cálculos computacionais podem ser demorados, pois a parte clássica que é tratada com Dinâmica Molecular ou Monte Carlo, exige um grande número de passos na simulação para que seja representativa. Também um cálculo quântico é feito a cada passo clássico, o que aumenta bastante a exigência computacional. E como os cálculos são feitos durante a simulação, também não há garantia de convergência da simulação.

Como uma alternativa ao QM/MM convencional, o método S-QM/MM busca evitar tais problemas e tornar os cálculos mais eficientes. No S-QM/MM as partes clássica 
e quântica são calculadas de forma desacoplada e sequencialmente. Agora os cálculos quânticos são feitos após a realização das simulações claśsicas. Numa primeira etapa uma simulação clássica de Monte Carlo ou Dinâmica Molecular é realizada. Cada configuração gerada é um conjunto das coordenadas de todos os átomos e moléculas presentes na simulação. Do total de configurações geradas é possível extrair configurações estatisticamente descorrelacionadas entre si e numa segunda etapa, são feitos cálculos quânticos sobre estas configurações.As propriedades do sistema molecular estudado são obtidas como médias simples sobre o número de configurações.

As moléculas são tratadas como rígidas durante toda a simulação, o que não ocorre no caso de Dinâmica Molecular. Neste trabalho as simulações clássicas foram feitas com o Método de Monte Carlo e utilizando o programa DICE [27].

Sendo $L$ o número de configurações, o que define o tamanho da simulação, o valor médio $\langle f\rangle$ de uma propriedade obtida da simulação é dado por

$$
\langle f\rangle_{L}=\frac{1}{L} \sum_{i=1}^{L} f_{i}
$$

Para o caso da energia, teremos por exemplo:

$$
\langle U\rangle_{L}=\frac{1}{L} \sum_{i=1}^{L} U_{i}
$$

e a variância da média

$$
\left\langle\delta U^{2}\right\rangle_{L}=\frac{1}{L} \sum_{i=1}^{L}\left(U_{i}-\left\langle U^{2}\right\rangle_{L}\right)^{2}=\left\langle U^{2}\right\rangle_{L}-\langle U\rangle_{L}^{2}
$$

O método S-QM/MM possui algumas vantagens. Com apenas uma pequena amostra das configurações geradas na simulação clássica, é possível obter resultados convergidos com poucos cálculos quânticos (entre 100 e 150 cálculos).

Uma desvantagem do método S-QM/MM é que como os cálculos são feitos de forma 
sequencial, não há polarização mútua entre o soluto e o solvente. Uma solução possível para isto, é colocar a polarização já inicialmente, ou seja, obtendo-se a geometria e as cargas do soluto em meio contínuo utilizando o método PCM.

Numa outra solução, é feito um cálculo quântico em fase gasosa e com isso se determina as cargas iniciais da simulação. Realiza-se uma simulação e após isto, determinamos novamente as cargas usando o método ASEC [28]. O ASEC, Average Solvent Electrostatic Configuration, foi proposto pelo nosso grupo e tem como idéia principal considerar uma configuração média para o solvente. No ASEC as configurações estatisticamente descorrelacionadas que foram selacionadas são sobrepostas e irão representar as moléculas de solvente como cargas pontuais normalizadas (divididas pelo número de configurações). Em seguida é feito um nova simulação e da mesma maneira calculam-se novas cargas. Este procedimento continua até a convergência do momento de dipolo. Desta maneira é feito um único cálculo da propriedade de interesse, utilizando-se uma configuração média. Isto é mais eficiente computacionalmente, pois do contrário seriam feitos vários cálculos com o solvente sendo representado por cargas pontuais para se obter o mesmo valor médio.

\subsection{A Simulação Computacional}

Utilizando o programa DICE [27], desenvolvido pelo nosso grupo, são feitas as simulações clássicas. O programa irá gerar uma configuração, ou seja, um conjunto de todos os átomos e moléculas da simulação, que será distribuída dentro de uma caixa cúbica.

A caixa cúbica será replicada em todas as direções, para com isso se evitar os efeitos de borda. Isto é conhecido como Método das Imagens [2] e garante a condição periódica de contorno que se uma molécula sair por um lado da caixa, a sua réplica é imediatamente reintroduzida pelo lado oposto. É preciso estabelecer um raio de corte 


\section{Simulação Computacional de Líquidos e o Método Sequencial QM/MM}

$r_{c}$, que será a distância máxima possível para a qual poderá ocorrer as interações entre os átomos. Além do raio de corte não se computa mais nenhuma interação e com isso temos uma econômia de cálculo computacional. O procedimento geralmente usado é considerar o raio de corte como metade da aresta da caixa cúbica.

\begin{tabular}{|c|c|c|}
\hline 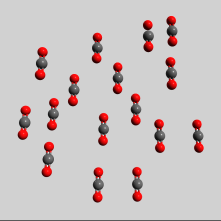 & 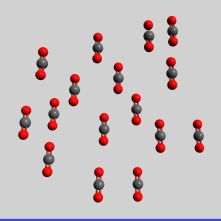 & 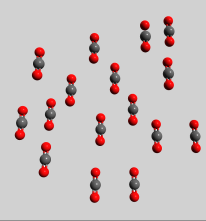 \\
\hline 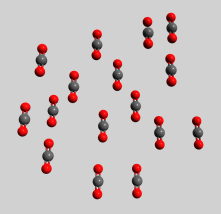 & & 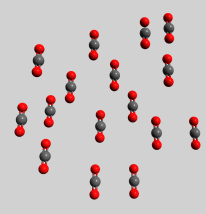 \\
\hline 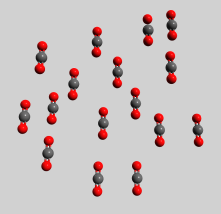 & 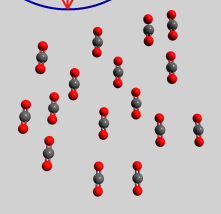 & 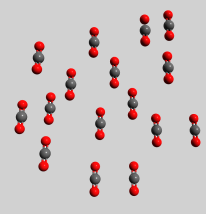 \\
\hline
\end{tabular}

Figura 2.4: Representação esquemática da caixa de simulação.

A caixa de simulação está localizada no centro e suas réplicas são projetadas em todas as direções. Isto introduz as condições periódicas de contorno que se uma molécula sair por um lado, a sua réplica entra pelo lado oposto. A interação entre átomos só pode ocorrer a uma distância menor que o raio de corte $r_{c}$. Desta forma a interação entre átomos distantes pela seta verde pode ocorrer, mas nada ocorre no caso da seta azul. Também consideramos um raio de sobreposição (overlap) igual a 0.8 Å, que estabelece a distância mínima para interação. Se em uma dada configuração a distância entre dois átomos de moléculas distintas é menor que $0.8 \AA$, essa configuração será rejeitada. Isto porque para uma distância tão pequena de interação, a repulsão será muito forte e aumentará muito a energia da configuração.

É preciso optar por um ensemble para se realizar a simulação. No ensemble isotérmico- 
isobárico (NPT) o número de partículas, pressão e temperatura são mantidos fixos. Já no ensemble canônico (NVT) o número de partículas, volume e temperatura são mantidos fixos. Embora no limite termodinâmico $(\mathrm{N} \rightarrow \infty)$ os ensembles sejam equivalentes, dependendo da propriedade a ser estudada um ensemble será mais vantajoso que o outro no caso finito. Na configuração inicial, algumas moléculas podem estar muito próximas uma das outras e essa proximidade gera uma energia muito alta. Por esse motivo, antes da simulação é feito uma etapa de termalização para que o sistema atinja o equilíbrio térmico. Esse resfriamento é feito de forma que uma configuração gerada só é aceita se diminuir a energia. Posteriormente é feito a termalização, mas as configurações geradas pela termalização não farão parte dos cálculos das propriedades a serem estudadas. Após a termalização, as configurações serão geradas através de um processo Markoviano e serão estas configurações que entrarão nos cálculos das propriedades.

\subsection{O Método Monte Carlo}

Podemos dizer que obter a estrutura de um sistema líquido, é saber como estão organizados seus átomos e moléculas numa certa região. No nosso caso, conhecendose as coordenadas dos átomos e moléculas dentro da caixa de simulação, temos uma configuração e para se obter as propriedades do sistema líquido, são necessárias muitas configurações. Para gerar as configurações utilizamos o Método de Monte Carlo [2].

A função de partição para um sistema com hamiltoniano $H$ é dada por [2]

$$
Z=\iint e^{-H / k T} d r d \rho
$$

Sendo $U(r)$ o potencial de interação, para um número finito de configurações, a média de uma grandeza é 


$$
\langle F\rangle=\lim _{N \rightarrow \infty} \frac{\sum_{i=1}^{N} F(r) e^{(-U(r) / k T)}}{\sum_{i=1}^{N} e^{(-U(r) / k T)}}
$$

As configurações serão escolhidas com probabilidade dada pelo fator de Boltzmann $e^{(-U(r) / k T)}$ e desta forma evita-se configurações pouco prováveis no cálculo de médias simples das propriedades. Isto é conhecido como método de amostragem de Metrópolis [2] [29]. Num processo Markoviano, cada configuração gerada depende apenas daquela que a precede. O algoritmo de amostragem de Metropolis será utilizado como um critério de aceitação ou rejeição das configurações geradas, dependendo da diferença de energia $\Delta U$ entre as configurações. Nosso processo para gerar as configurações compõem-se das seguintes etapas:

1. A partir de uma configuração inicial, é selecionado uma molécula e será feito uma translação e uma rotação. O centro de massa da molécula é transladado por uma distância que é sorteada e escolhe-se um eixo que será rotacionado num ângulo de $-15^{\circ}$ e $15^{\circ}$. No caso do ensemble NPT, o volume da caixa também deve ser variado. Com isto uma nova configuração aleatória é gerada.

2. Será calculado a energia dessa nova configuração. Se a energia for menor que a energia da configuração anterior, essa nova configuração é aceita.

3. Se a energia da nova configuração é maior que a energia da configuração anterior, calcula-se a probabilidade $e^{(-\Delta U(r) / k T)}$ de transição de uma nova configuração para outra e é gerado um número aleatório $p$ entre 0 e 1 . Se a probabilidade é maior que esse número, ou seja, $e^{(-\Delta U(r) / k T)} \geq p$ essa nova configuração é aceita e retomamos ao processo para se gerar outras configurações. Se $e^{(-\Delta U(r) / k T)} \leq p$ a configuração atual é mantida. 
Uma vez que todas as moléculas do sistema passarem por esse ciclo, temos um passo de Monte Carlo. Para melhorar a amostragem do espaço de configurações, as simulações geralmente são feitas com ordem de $10^{5}$ passos/molécula. No método Monte Carlo usado, as moléculas são consideradas rígidas. Se fosse considerado também a flexibilidade das moléculas, teríamos um aumento significativo do custo computacional, já que teríamos de considerar outros fatores como variações translacionais e orientacionais. As propriedades termodinâmicas do sistema são obtidas como médias simples

$$
\langle F\rangle=\frac{1}{N} \sum_{i=1}^{N} F_{i}
$$

(Onde $N$ é o número de configurações)

A variância de $F$ é

$$
\left\langle\delta F^{2}\right\rangle=\frac{1}{N} \sum_{i=1}^{F}\left(F_{i}-\left\langle F^{2}\right\rangle\right)^{2}=\left\langle F^{2}\right\rangle-\langle F\rangle^{2}
$$

\subsection{O Potencial Interatômico}

O potencial de interação nos fornece a maneira na qual os átomos ou moléculas irão interagir entre si. Poderíamos obter o potencial resolvendo-se a equação de Schroedinger, mas isto se torna complicado para sistemas líquidos pois teríamos que tratar de muitas partículas. De forma geral podemos escrever:

$$
U=U_{\text {intra }}+U_{\text {inter }}
$$

O termo $U_{\text {intra }}$ refere-se a interações intramoleculares e a energia intramolecular de cada molécula permanece a mesma durante toda a simulação, já que estamos considerando moléculas rígidas. Já o termo $U_{\text {inter }}$ refere-se a interações intermoleculares, 
como interações de dois corpos, três corpos etc. Um potencial geralmente usado em simulações de sistemas líquidos é o potencial de Lennard-Jones [2] mais o potencial devido a interação de Coulomb

$$
U\left(r_{i j}\right)=4 \varepsilon_{i j}\left[\left(\frac{\sigma_{i j}}{r_{i j}}\right)^{12}-\left(\frac{\sigma_{i j}}{r_{i j}}\right)^{6}\right]+\frac{q_{i} q_{j}}{4 \pi \epsilon r_{i j}}
$$

onde $r_{i j}$ é a distância entre as partículas interagentes e $\sigma$ e $\varepsilon$ são parâmetros dados pelas expressões

$$
\sigma_{i j}=\left(\sigma_{i} \sigma_{j}\right)^{1 / 2} ; \varepsilon_{i j}=\left(\varepsilon_{i} \varepsilon_{j}\right)^{1 / 2}
$$

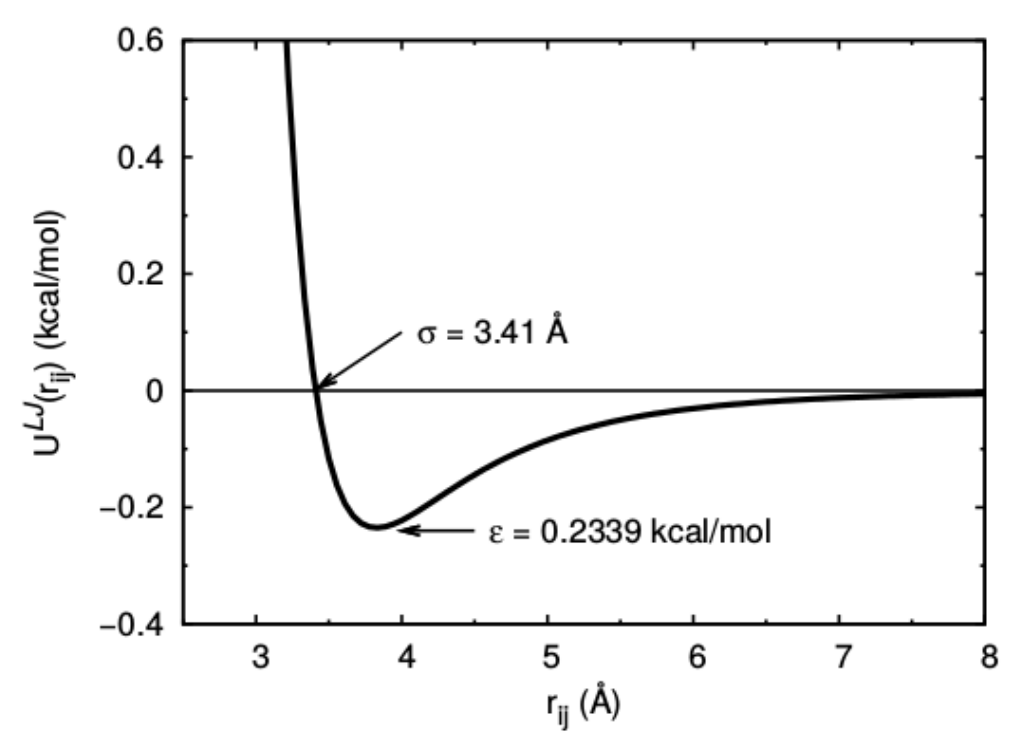

Figura 2.5: Exemplo de uma curva do Potencial de Lennard-Jones. Nesta caso tratamos do argônio em fase líquida [30].

Na figura (2.6) acima, podemos observar que a forma do potencial de LennardJones apresenta componentes típicos de interações intermoleculares. O parâmetro $\varepsilon$ está relacionado à profundidade do poço, ou seja, é a energia de ligação. Já o parâmetro $\sigma$ é a distância entre os sítios, ou a posição dos átomos, onde as forças 
atrativas e repulsivas são iguais o que torna o potencial nulo. Da relação (2.9) o termo de Coulomb descreve as interações eletrostáticas. Já o potencial de Lennard-Jones possui um termo atrativo, com uma dependência em $r^{-6}$ e corresponde aos termos de van der Waals, descrevendo a atração a longas distâncias. O termo positivo com dependência em $r^{-12}$ está relacionado à repulsão a curtas distâncias.

\subsection{A Função de Distribuição Radial de Pares $G(r)$ e a Autocorrelação da Energia}

\subsubsection{A Função de Distribuição de Pares G(r)}

A função de distribuição radial de pares $(G(r)$ ou RDF) nos fornece a distribuição de moléculas de solvente em torno do soluto, ou seja, temos uma informação sobre as propriedades estruturais do sistema líquido. Essa função descreve como varia a densidade atômica em função da distância a partir de um ponto específico, tal como um átomo qualquer ou o centro de massa de uma molécula do sistema. A integral abaixo nos define a função $G(r)$, como a integral da parte configuracional sobre os átomos, com excessão de dois, que estão distantes a uma distância $r$ um do outro:

$$
G\left(\mathbf{r}_{1}, \mathbf{r}_{2}\right)=\frac{N(N-1)}{\rho^{2} Z} \int e^{-U / k T} d \mathbf{r}_{3} d \mathbf{r}_{4} \ldots d \mathbf{r}_{N}
$$

No gráfico de $G(r)$ também é possível se fazer uma análise para determinar como está ordenado o meio que envolve o átomo ou molécula de referência. É possível observar uma estrutura de camadas no gráfico de uma $G(r)$ e integrando a expressão (2.11) ao longo de uma camada esférica, é possível obter o número de átomos em torno de um átomo de referência, ou seja, obtemos o número de coordenação, dado por:

$$
N(r)=4 \pi \frac{N}{V} \int_{0}^{r} G(r) r^{2} d r
$$




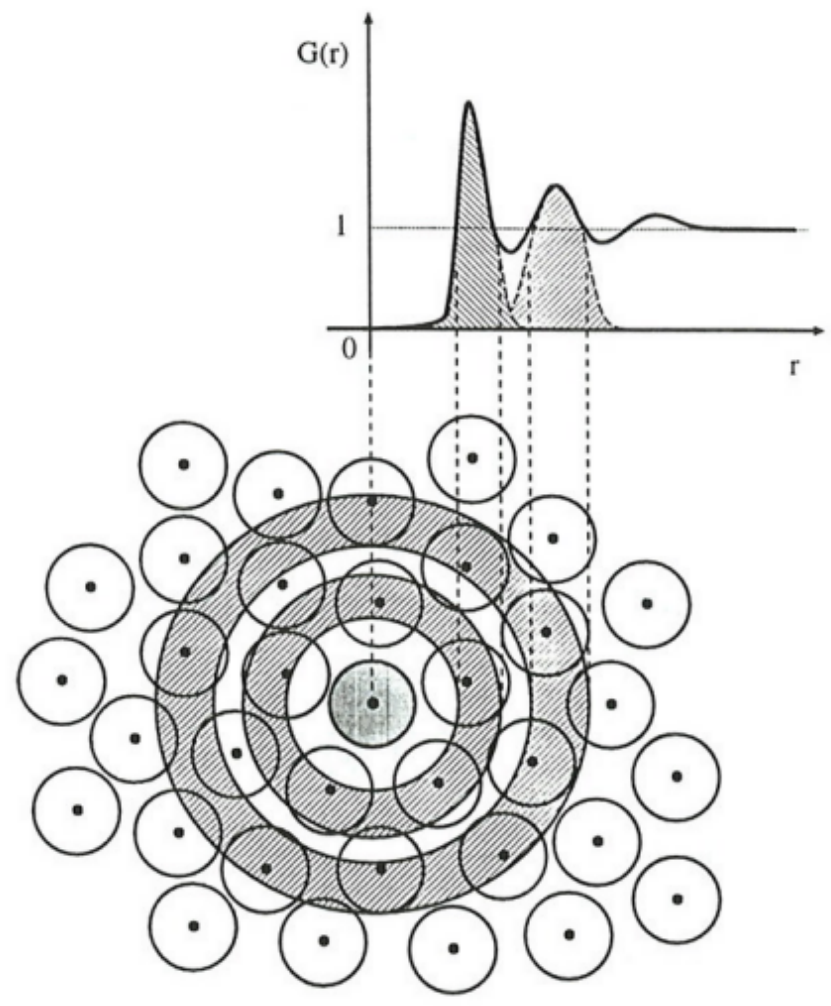

Figura 2.6: Representação de uma função $G(r)$ entre o centro de massa do soluto e o centro de massa das moléculas do solvente. O primeiro máximo representa a primeira camada de solvatação. A função $G(r)$ nos dá informação sobre a estrutura em volta de um átomo de referência. Também podemos ver a estrutura de camadas e os picos da função representam exatamente a estrutura de camadas em volta de um átomo. Figura extraída da referência $[14]$.

Temos que $G(r) \rightarrow 0$ quando $r \rightarrow 0$, pois caso contrário os átomos estariam se sobrepondo. Também $G(r) \rightarrow 1$ quando $r \rightarrow \infty$, ou seja, para grandes distâncias a estrutura em relação a um átomo de referência está desordenada, tendendo a uma distribuição de gás ideal. Portanto, para se estudar as propriedades estruturais, comumente é usada a função de distribuição radial de pares $G(r)$. Esta função também pode ser obtida de experiências com difração de raio-X e neutrons [31] e espalhamento de raio-X [32] [33].

A análise teórica da estrutura de camadas em torno do soluto, geralmente é feita 
utilizando-se uma $G(r)$ entre os centros de massa. Neste caso, a função nos mostra como as moléculas do solvente estão estruturadas em torno do soluto como um todo. Porém, se o soluto for uma molécula grande e de formato alongado, a $G(r)$ de centro de massa não representará corretamente a estrutura do solvente ao redor do soluto, já que não podemos mais considerar uma simetria radial devido a forma do soluto. Nesta situação, teríamos moléculas de solvente que se encontram numa mesma casca esférica dada pela $G(r)$ de centro de massa, a distâncias diferentes da molécula soluto. Isso mostra que a $G(r)$ de centro de massa é inadequada para analisar a distribuição do solvente ao redor de moléculas alongadas.

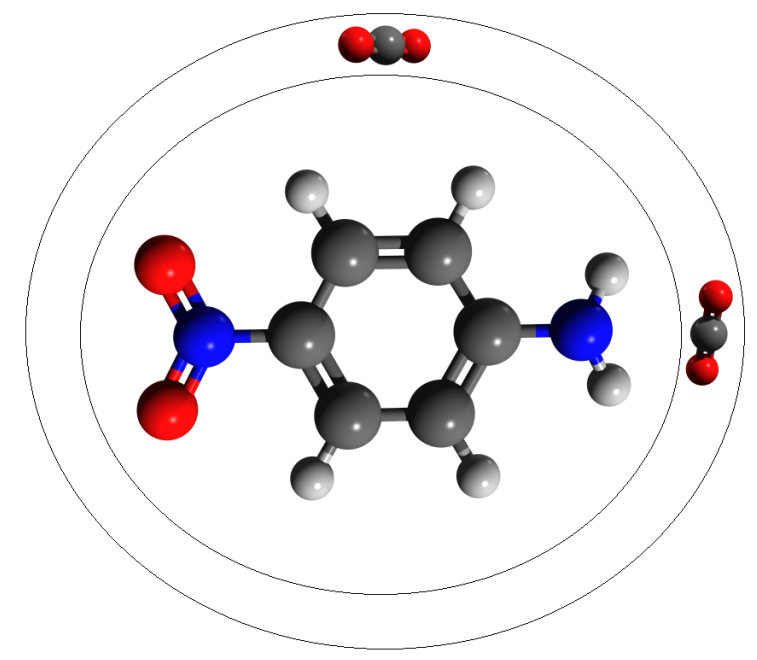

Figura 2.7: Representação esquemática da $G(r)$ de centro de massa. Figura baseada na referência [86].

Para esse tipo de situação, ou seja, moléculas grandes e de formato alongado, uma maneira melhor de analisar as camadas de solvente é por meio da função de distribuição de mínima distância (MDDF) [73]. Nesse caso a distância entre duas moléculas é dada pela menor dentre todas as distâncias possíveis entre os átomos de uma e os átomos da outra. Ao selecionar as camadas de solvente com base na MDDF elas terão o formato da molécula de soluto. 


\subsubsection{Autocorrelação da Energia}

Após realizar uma simulação com o Método de Monte Carlo, são geradas muitas configurações (da ordem de $10^{8}$ ). Não seria possível trabalhar com todas essas configurações, utilizando-se métodos de Mecânica Quântica. Uma solução é tomar apenas um conjunto de configurações estatisticamente descorrelacionadas. Para se determinar estas configurações nós utilizamos a função de autocorrelação de energia

$$
C(t)=\frac{\left\langle\delta E_{n} \delta E_{n+t}\right\rangle}{\left\langle\delta E^{2}\right\rangle}=\frac{\sum_{n}\left(E_{n}-\langle E\rangle\right)\left(E_{n+t}-\langle E\rangle\right)}{\sum_{n}\left(E_{n}-\langle E\rangle\right)^{2}}
$$

Onde $E_{n}$ é a energia da configuração $n$ e $E_{n+t}$ a energia da configuração que foi gerada $t$ passos de Monte Carlo depois. Com isso, se tivermos configurações separadas por um número pequeno de passos de Monte Carlo, tais configurações terão uma correlação próxima a 1, o que significa que se utilizarmos tais configurações não teríamos novas informações estatísticas. Para processos Markovianos, $C(t)$ apresenta um decaimento exponencial do tipo

$$
C(t)=\sum_{k} c_{k} e^{-t / \tau_{k}}
$$

O intervalo de correlação $\tau$ é definido pela integral da função de autocorrelação

$$
\tau=\int_{0}^{\infty} C(t) d t
$$

Em nosso grupo consideramos como estatisticamente descorrelacionadas as correlações separadas por um intervalo tal que a correlação seja menor que 13\%. Apenas as configurações estatisticamente descorrelacionadas serão utilizadas nos cálculos quânticos. 


\section{Métodos Quânticos de estrutura eletrônica}

Sabemos que uma solução exata da equação de Schroedinger não pode ser obtida para sistemas de muitos corpos. Como desde sua origem a Mecânica Quântica busca obter as propriedades moleculares a partir da solução da equação de Schroedinger, foi preciso desenvolver métodos quânticos aproximativos para se buscar essa solução. Tais métodos puderam ser implementados de forma mais direta com o avanço computacional. Podemos dizer que os métodos quânticos são divididos em métodos ab initio, ou de primeiros princípios, e os métodos semi-empíricos. Nos métodos ab initio são utilizadas apenas as constantes universais, por exemplo a massa e carga do elétron, velocidade da luz c e etc. No caso semi-empírico parametrizam-se algumas propriedades do sistema e tais parâmetros são obtidos de resultados experimentais ou por meio de cálculos ab initio mesmo. Neste capítulo alguns métodos quânticos serão tratados, como por exemplo a aproximação de Born-Oppenheimer e o método de Hartree-Fock. Iremos discutir brevemente a Teoria de Perturbação de Møller Plesset e a Teoria do Funcional da Densidade. Ao final do capítulo falamos um pouco sobre o funcional híbrido $\boldsymbol{C A M - B 3 L Y P}$ que foi utilizado neste trabalho. 


\subsection{A Aproximação de Born-Oppenheimer}

A equação estacionária de Schroedinger para um sistema molecular pode ser dada por

$$
H(r, R) \Psi(r, R)=E \Psi(r, R)
$$

onde $r$ representa a coordenada coletiva para os elétrons, $R$ é a coordenada coletiva para os núcleos, $H$ é o operador Hamiltoniano do sistema e $\Psi$ é sua função de onda.

É através da equação de Schroedinger que podemos obter as propriedades moleculares do sistema, tais como a estrutura eletrônica, os espectros de absorção e emissão e também podemos obter as propriedades estruturais como as distâncias, ângulos e diedros.

Considerando o sistema de unidades atômicas $a . u$, ou seja, $e=\hbar=a_{0}=1$ e 1 hartree $\cong 27.21 \mathrm{eV}$, também sem considerar efeitos relativísticos, o operador Hamiltoniano $H$ para um sistema com $N$ núcleos e $n$ elétrons pode ser escrito de forma geral como

$$
H=-\sum_{A=1}^{N} \frac{1}{2 M_{A}} \nabla_{A}^{2}-\frac{1}{2} \sum_{i}^{N} \nabla_{i}^{2}+\sum_{i=1}^{n} \sum_{j<1}^{N} \frac{1}{r_{i j}}+\sum_{A=1}^{N} \sum_{B<A}^{N} \frac{Z_{A} Z_{B}}{R_{A B}}-\sum_{i=1}^{n} \sum_{A=1}^{N} \frac{Z_{A}}{r_{i A}}
$$

Sendo:

1. A energia cinética dos núcleos:

$$
T_{R}=-\sum_{A=1}^{N} \frac{1}{2 M_{A}} \nabla_{A}^{2}
$$

2. A energia cinética dos elétrons:

$$
T_{r}=-\frac{1}{2} \sum_{i}^{N} \nabla_{i}^{2}
$$


3. A energia potencial eletrostática:

$$
V_{e}=\sum_{i=1}^{n} \sum_{j<1}^{N} \frac{1}{r_{i j}}
$$

4. A energia potencial nuclear:

$$
V_{N}=\sum_{A=1}^{N} \sum_{B<A}^{N} \frac{Z_{A} Z_{B}}{R_{A B}}
$$

5. A energia potêncial de atração elétron-núcleo

$$
V_{e N}=-\sum_{i=1}^{n} \sum_{A=1}^{N} \frac{Z_{A}}{r_{i A}}
$$

Os índices minúsculos referem-se aos elétrons e os maiúsculos referem-se aos núcleos. Os termos $Z_{A}$ e $Z_{B}$ são os números atômicos dos átomos $A$ e $B$, enquanto que $R_{A B}$ é a distância entre tais núcleos. O termo $r_{i j}$ é a distância entre os elétrons $i$ e $j$ e $r_{i A}$ é a distância entre o elétron e o núcleo $A$. A massa do núcleo de $A$ é dada por $M_{A}$.

A relação (3.2) é muito complexa, já que o operador Hamiltoniano leva em conta termos cinéticos para os elétrons e núcleos, potenciais de interação entre os elétrons, entre núcleos e entre elétrons e núcleos.

De forma resumida temos:

$$
H(r, R)=T_{r}+T_{R}+V_{r R}
$$

sendo $T_{r}$ o operador de energia cinética dos elétrons; $T_{R}$ é o operador de energia cinética dos núcleos; $V_{r R}$ engloba os potenciais. Porém o acoplamento entre os movimentos nuclear e eletrônico gera dificuldades para se resolver a relação (3.3). É preciso propor que tais movimentos possam ser separados e com isso escrevemos uma função de onda total como um produto entre uma função de onda para os núcleos e outra para os elétrons, sendo que esta última é parametricamente dependente da posição dos 
núcleos.

$$
\Psi(r, R)=\psi_{e}(r ; R) \chi_{N}(R)
$$

onde $\psi_{e}(r ; R)$ é uma função que descreve o movimento eletrônico, dependendo parametricamente das coordenadas nucleares $R$, e $\chi_{N}(R)$ descreve o movimento nuclear. Esta é a aproximação de Born-Oppenheimer (BO), baseando-se no fato de que os elétrons possuem massa muito menor que os núcleos e por isso não irão interferir significativamente no movimento dos núcleos [34]. Considerando que $\psi_{e}(r ; R)$ varia lentamente com $R$, ou seja, a função de onda eletrônica varia lentamente com as coordenadas nucleares, temos que:

$$
T_{R} \psi_{e}(r ; R) \chi_{N}(R) \cong \psi_{e}(r ; R) T_{R} \chi_{N}(R)
$$

Utilizando-se separação de variáveis, obtemos então equações separadas para o movimento eletrônico e nuclear:

$$
\begin{gathered}
\left(T_{r}+V_{r R}\right) \psi_{e}(r ; R)=E_{e}(R) \psi_{e}(r ; R) \\
\left(T_{R}+E_{e}(R)\right) \chi_{N}(R)=E_{N} \chi_{N}(R)
\end{gathered}
$$

A relação (3.6) é na verdade uma equação estacionária de Schroedinger para os elétrons e pode ser resolvida com valores fixos de $R$ :

$$
H_{e}(r ; R) \psi_{e}(r ; R)=E_{e}(R) \psi_{e}(r ; R)
$$

onde $E_{e}(R)$ é a energia total eletrônica e o hamiltoniano eletrônico $H_{e}(r ; R)$ não possui o termo de energia cinética dos núcleos (os núcleos são fixados para o cálculo da função de onda eletrônica).

Pela relação (3.7) vemos que ao resolver o problema eletrônico, a relação para os núcleos pode ser resolvida utilizando-se $E_{e}(R)$ como um potencial para o movimento 
dos núcleos, ou seja, estudamos o problema nuclear a partir do problema eletrônico. A aproximação de Born-Oppenheimer se torna inválida se houver um forte acoplamento entre diferentes estados eletrônicos [35] [36]. Um cruzamento entre curvas de potenciais é um exemplo que leva a um forte acoplamento. Os métodos seguintes buscarão uma solução aproximada para o problema eletrônico.

\subsection{Método de Hartree-Fock}

Como já dito, a obtenção de soluções da equação de Schroedinger é o objetivo da mecânica quântica, pois com isso podemos determinar as propriedades de sistemas atômicos e moleculares. Como a solução exata em geral não é factível, torna-se necessário a utilização de métodos aproximativos. O método de Hartree-Fock (HF) nos fornece uma boa solução aproximada para o problema de muitos elétrons. Para se resolver a equação de Schroedinger (3.1) para um sistema de muitos elétrons, a função de onda deve ser antissimétrica com relação à troca de coordenadas de dois elétrons e é escrita como um determinante de Slater

$$
\Psi=\frac{1}{\sqrt{N !}}\left|\begin{array}{cccc}
\psi_{i}(1) & \psi_{j}(1) & \ldots & \psi_{k}(N) \\
\psi_{i}(2) & \psi_{j}(2) & \ldots & \psi_{k}(N) \\
\vdots & \vdots & \ddots & \vdots \\
\psi_{i}(N) & \psi_{j}(N) & \ldots & \psi_{k}(N)
\end{array}\right|
$$

onde $\psi^{\prime} s$ são funções de onda das coordenadas espaciais e do spin de um único elétron (spin-orbitais eletrônicos).

Utilizando este determinante na relação (3.6) obtemos [35] [36]

$$
E=\sum_{i=1}^{N}\left\langle\varphi_{i}\left|-\frac{\nabla_{i}^{2}}{2}-\sum_{A=1}^{N} \frac{Z_{A}}{r_{i A}}\right| \varphi_{i}\right\rangle+\frac{1}{2} \sum_{i, j}^{n}\left[\left\langle\varphi_{i}\left|J_{j}-K_{j}\right| \varphi_{i}\right\rangle\right]
$$


Na relação acima temos ainda que:

$$
\begin{aligned}
J_{j}(1) \varphi_{i}(1) & =\left\langle\varphi_{j}(2)\left|\frac{1}{r_{12}}\right| \varphi_{i}(2)\right\rangle \varphi_{i}(1) \\
K_{j}(1) \varphi_{i}(1) & =\left\langle\varphi_{j}(2)\left|\frac{1}{r_{12}}\right| \varphi_{i}(2)\right\rangle \varphi_{j}(1)
\end{aligned}
$$

onde o termo $\hat{J}_{j}$ é o operador de Coulomb e se relaciona com a repulsão eletrônica, representando um potencial médio de Coulomb dada à densidade eletrônica. Já o termo $\hat{K}_{j}$ (termo de troca/exchange) não tem uma explicação ou algum exemplo clássico, sendo apenas associado com a antissimetria da função de onda.

Para cada $\varphi_{i}$ vale a relação abaixo [34] [37], conhecida com equação de Hartree-Fock:

$$
F_{i} \varphi_{i}=\varepsilon_{i} \varphi_{i}
$$

onde o operador de Fock $\hat{F}_{i}$ é dado por:

$$
\hat{F}_{i}=\sum_{i}\left\{h_{i}+\sum_{j}\left(2 J_{i j}-K_{i j}\right)\right\}
$$

Onde $h_{i}=T_{e}+V_{e N}$.

Na relação (3.14) temos um potencial efetivo, $\sum_{j}\left(2 J_{i j}-K_{i j}\right)$, de forma que o elétron sente os outros elétrons através de um campo médio e não na forma individual. Para resolver a equação de Fock, damos uma condição inicial para a função de onda $\varphi_{i}^{0}$ e calculamos o operador de Fock $\hat{F}_{i}$. Em seguida resolvemos a relação (3.13) e encontramos uma outra função de onda $\varphi_{i}^{1}$. Calcula-se um novo operador de Fock $\hat{F}_{i}$ para esta nova função e resolve-se novamente a relação (3.13). Esse processo iterativo mantém-se até que se obtenha uma convergência. Tal procedimento é chamado de Campo Auto Consistente.

Podemos tomar ainda uma aproximação para os orbitais moleculares $\varphi_{i}$ e passar a escrevê-los como uma combinação linear de orbitais atômicos (LCAO - Linear Com- 
bination of Atomic Orbitals

$$
\varphi_{i}=\sum_{\mu} c_{\mu i} \phi_{\mu}
$$

onde $\phi_{\mu}$ são um conjunto de funções conhecidas e os coeficientes $c_{\mu i} s$ são determinados pelo princípio variacional.

Isto levou ao método de Hartree-Fock-Roothan [34] que é eficiente computacionalmente e é o método que utilizamos atualmente. Este método utiliza um processo matricial para se resolver a equação de Hartree-Fock e se determinar os coeficientes $c_{\mu i} s$.

\subsection{Teoria de Perturbação de Møller Plesset}

O Hamiltoniano do sistema será escrito como:

$$
\hat{H}=\hat{H}_{0}+\lambda \hat{V}
$$

O termo $\hat{H}_{0}$ é o Hamiltoniano já conhecido, ou seja, sabemos resolver a equação de Schroedinger neste caso e conhecemos os autovalores e autofunções. Portanto, este é o termo não-perturbado. O outro termo $(\lambda \hat{V})$ é o operador que irá representar a perturbação em $\hat{H}_{0}$.

A idéia central da Teoria de Perturbação é buscar melhorar as autofunções e autovalores do Hamiltoniano $\hat{H}_{0}$ (não-perturbado), de modo que tenhamos uma boa aproximação para o Hamiltoniano $\hat{H}$ (perturbado). Se o parâmetro $\lambda$ é pequeno, ou seja, assumindo que a perturbação seja pequena, podemos expandir os autovalores e autofunções como uma expansão de Taylor. Este formalismo é conhecido como Teoria de Perturbação de Rayleigh-Schroedinger [35] [38].

Sendo $\psi_{n}$ as autofunções e $E_{n}$ os autovalores, teremos que: 


$$
\begin{gathered}
\psi_{n}=\psi_{n}^{(0)}+\lambda \psi_{n}^{(1)}+\lambda^{2} \psi_{n}^{(2)}+\lambda^{3} \psi_{n}^{(3)}+\cdots+\lambda^{k} \psi_{n}^{(k)} \\
E_{n}=E_{n}^{(0)}+{ }_{n}^{(1)}+\lambda^{2} E_{n}^{(2)}+\lambda^{3} E_{n}^{(3)}+\cdots+\lambda^{k} E_{n}^{(k)}
\end{gathered}
$$

Aqui os termos $\psi_{n}^{(0)}$ e $E_{n}^{(0)}$ se tratam do caso não-perturbado, enquanto que os demais termos representam os n-ésimos estados perturbados.

As correções para a energia e para a função de onda são dadas por [39] [40]:

\section{Autovalores (energia)}

Primeira ordem:

$$
E_{n}^{(1)}=\left\langle\psi_{n}^{(0)}|\hat{V}| \psi_{n}^{(0)}\right\rangle
$$

Segunda ordem:

$$
E_{n}^{(2)}=\left\langle\psi_{n}^{(0)}|\hat{V}| \psi_{n}^{(1)}\right\rangle=\sum_{m \neq n} \frac{\left|\left\langle\psi_{m}^{(0)}|\hat{V}| \psi_{n}^{(0)}\right\rangle\right|^{2}}{E_{n}^{(0)}-E_{m}^{(0)}}
$$

\section{Autofunções (funções de onda)}

Primeira ordem:

$$
\psi_{n}^{(1)}=\sum_{m \neq n} \frac{\left\langle\psi_{m}^{(0)}|\hat{V}| \psi_{n}^{(0)}\right\rangle}{E_{n}^{(0)}-E_{m}^{(0)}} \psi_{m}^{(0)}
$$

Segunda ordem:

$$
\psi_{n}^{(2)}=\sum_{l, m \neq n} \frac{\left\langle\psi_{m}^{(0)}|\hat{V}| \psi_{l}^{(0)}\right\rangle\left\langle\psi_{l}^{(0)}|\hat{V}| \psi_{n}^{(0)}\right\rangle}{\left(E_{n}^{(0)}-E_{l}^{(0)}\right)\left(E_{n}^{(0)}-E_{m}^{(0)}\right)} \psi_{m}^{(0)}-E_{n}^{(1)} \sum_{m \neq n} \frac{\left\langle\psi_{m}^{(0)}|\hat{V}| \psi_{n}^{(0)}\right\rangle}{\left(E_{n}^{0}-E_{m}^{0}\right)^{2}} \psi_{m}^{(0)}
$$

Para sistemas eletrônicos de muitos corpos, normalmente a Teoria de Perturbação utilizada é a de Møller-Plesset [41]. A teoria de Perturbação de Møller-Plesset baseiase na teoria de Rayleigh-Schroedinger, mas considera o hamiltoniano não-perturbado $\hat{H}_{0}$ como a soma de operadores de Fock [35]

$$
\hat{H}_{0}=\sum_{\mu=1}^{N} \hat{F}(\mu)=\sum_{\mu=1}^{N}\left\{\hat{h}(\mu)+\sum_{j=1}^{N}\left[\hat{J}_{j}(\mu)-\hat{K}_{j}(\mu)\right]\right\}
$$

Neste formalismo verifica-se que a correção de energia em primeira ordem será a própria 
energia de Hartree-Fock para o estado fundamental, ou seja, o método de Hartree-Fock é correto até a primeira ordem

$$
E_{0}+E_{1}=E_{H F}
$$

Já a correção de segunda ordem $M P \mathscr{2}$ exige apenas excitações duplas, sendo dada por:

$$
E^{(2)}=\sum_{\substack{a<b \\ r<s}} \frac{\left|\left\langle\psi_{0}|\hat{V}| \psi_{a b}^{r s}\right\rangle\right|}{E_{0}-E_{r s}}
$$

Para correções de ordens superiores, será necessário excitações triplas, quadruplas etc... o que torna o método lento computacionalmente além de que não há garantia de convergência da série.

\subsection{Teoria do Funcional da Densidade}

Baseada em dois teoremas propostos por Hohenberg e Kohn [42], a teoria do Funcional da Densidade (DFT) descreve o sistema através da densidade eletrônica, ao contrário dos formalismos atuais que utilizam as funções de onda para descrevê-lo.

No caso do método de Hartree-Fock (HF), trabalhamos com um caso que busca transformar o problema de $n$ corpos em $n$ problemas de apenas um corpo. Já na DFT, ao invés de trabalharmos com uma função de onda de $3 n$ variáveis, iremos utilizar uma função de 3 variáveis que possa representar a densidade eletrônica.

Os dois teoremas citados anteriormente são [35] [36] [48]:

Teorema 3.1: O potencial externo $v(\mathbf{r})$ é um funcional único da densidade eletrônica $\rho(\mathbf{r}) ;$

Teorema 3.2: A energia do estado fundamental $\left(E_{0}[\rho]\right)$ é mínima para a densidade $\operatorname{exata}(\rho(\mathbf{r}))$,

$$
E[\rho]=\langle\psi|\hat{T}+\hat{U}+\hat{V}| \psi\rangle
$$


onde $\hat{T}+\hat{U}+\hat{V}$ é a energia cinética, energia de interação elétron-elétron e energia potencial respectivamente.

Para um determinado estado $\psi$, sua densidade será $\rho(\mathbf{r})$. Já a densidade $\rho_{0}$ vem do Hamiltoniano $\hat{H}=\hat{T}+\hat{U}+\hat{V}$. Temos então que:

$$
\left\{\begin{array}{l}
\text { Se } \rho \neq \rho_{0} \Rightarrow \psi \neq \psi_{0}, \log \sigma E>E_{0} \\
\text { Se } \rho=\rho_{0} \Rightarrow \psi=\psi_{0}, \log \sigma E=E_{0}
\end{array}\right.
$$

Reescrevendo a relação (3.26), temos que:

$$
E[\rho]=\langle\psi|\hat{T}+\hat{U}| \psi\rangle+\langle\psi|\hat{V}| \psi\rangle=F[\rho]+\langle\psi|\hat{V}| \psi\rangle
$$

onde $F[\rho]$ é um funcional universal válido para qualquer sistema coulombiano.

Da mesma maneira, para o estado fundamental temos:

$$
E\left[\rho_{0}\right]=F\left[\rho_{0}\right]+\left\langle\psi_{0}|\hat{V}| \psi_{0}\right\rangle
$$

Analisando o funcional $F[\rho]$, podemos explicitar a parte coulombiana deste funcional, já que as interações coulombianas são de longo alcance. Com isto temos:

$$
F[\rho]=\frac{1}{2} \iint \frac{\rho(\mathbf{r}) \rho\left(\mathbf{r}^{\prime}\right)}{\left|\mathbf{r}-\mathbf{r}^{\prime}\right|} d^{3} \mathbf{r} d^{3} \mathbf{r}^{\prime}+G[\rho]
$$

A energia pode ser reescrita como:

$$
E[\rho]=\int v(\mathbf{r}) \rho(\mathbf{r}) d^{3} \mathbf{r}+\frac{1}{2} \iint \frac{\rho(\mathbf{r}) \rho\left(\mathbf{r}^{\prime}\right)}{\left|\mathbf{r}-\mathbf{r}^{\prime}\right|} d^{3} \mathbf{r} d^{3} \mathbf{r}^{\prime}+G[\rho]
$$

onde $G[\rho]$ também é um funcional universal.

Podemos reescrever o funcional $G[\rho]$ da seguinte forma:

$$
G[\rho] \equiv T_{0}[\rho]+E_{x c}[\rho]
$$

O termo $T_{0}[\rho]$ é a energia cinética de um sistema de elétrons com densidade $\rho(\mathbf{r})$ não interagentes. Já $E_{x c}[\rho]$ é um funcional que contém a energia de troca e correlação de 
um sistema interagente com densidade $\rho(\mathbf{r})$.

Levando (3.31) em (3.30) temos que:

$$
E[\rho]=\int v(\mathbf{r}) \rho(\mathbf{r}) d^{3} \mathbf{r}+\frac{1}{2} \iint \frac{\rho(\mathbf{r}) \rho\left(\mathbf{r}^{\prime}\right)}{\left|\mathbf{r}-\mathbf{r}^{\prime}\right|} d^{3} \mathbf{r} d^{3} \mathbf{r}^{\prime}+T_{0}[\rho]+\int \rho(\mathbf{r}) E_{x c}(\rho(\mathbf{r})) d^{3} \mathbf{r}
$$

A densidade eletrônica pode ser representada por:

$$
\rho(\mathbf{r})=\sum_{i=1}^{N}\left|\psi_{i}(\mathbf{r})\right|^{2}
$$

Usando o vínculo de que a carga total seja fixa, ou seja, $\int \rho(\mathbf{r}) d^{3} \mathbf{r}=N$ e usando também o teorema variacional, podemos tomar uma variação de $E[\rho]$. A solução deste caso pode ser obtida resolvendo-se a equação de Schroedinger de uma partícula

$$
\underbrace{\left(-\frac{1}{2} \nabla^{2}+v^{K S}[\rho]\right)}_{\hat{h}^{K S}} \psi_{i}(\mathbf{r})=\epsilon_{i} \psi_{i}(\mathbf{r})
$$

onde $v^{K S}[\rho]$ é o potencial efetivo de Kohn-Sham, sendo dado por:

$$
\begin{gathered}
v^{K S}[\rho]=v(\mathbf{r})+\int \frac{\rho\left(\mathbf{r}^{\prime}\right)}{\left|\mathbf{r}-\mathbf{r}^{\prime}\right|} d^{3} \mathbf{r}^{\prime}+v_{x c}(\rho) \\
v_{x c}(\rho)=\frac{\delta E_{x c}}{\delta \rho}
\end{gathered}
$$

é o potencial de troca-correlação.

Estas relações geram um procedimento autoconsistente, pois para uma dada densidade eletrônica $\rho(\mathbf{r})$, é possível calcular o potencial efetivo $v^{K S}[\rho]$. Com isto, pode-se usar o Hamiltoniano $\hat{h}^{K S}$ e se calcular a função de onda $\psi_{i}$. Com a função de onda $\psi_{i}$ obtêm-se uma nova densidade $\rho(\mathbf{r})$. O resultado convergido é exato, já que não foi feita nenhuma aproximação.

Umas das críticas feitas ao método DFT está em como se representar o termo de troca e correlação $E_{x c}[\rho]$, pois não existe uma forma sistemática de construí-lo. Por exemplo, para se obter $v^{K S}[\rho]$ é preciso fazer uma escolha inicial do funcional de troca 
e correlação $E_{x c}[\rho]$. Existem várias aproximações para tal termo e um exemplo disto é a aproximação LDA, Local Density Approximation. Na aproximação LDA, a densidade eletrônica $\rho(\mathbf{r})$ é considerada igual a de um gás de elétrons homogêneo. Com isso a energia de troca e correlação é escrita como:

$$
E_{x c}[\rho]=\int \rho(\mathbf{r}) \epsilon_{x c}^{h}(\rho(\mathbf{r})) d^{3} \mathbf{r}
$$

onde $\epsilon_{x c}^{h}$ é a energia de troca e correlação por elétron de um sistema de gás de elétrons homogêneo com densidade $\rho=\rho(\mathbf{r})$.

Existem outras aproximações para o termo $E_{x c}[\rho]$, como a aproximação LSDA (Local Spin Density Approximation) e também a Aproximação de Gradiente Generalizado (GGA) [44].

É possível ainda estender este tratamento feito pela DFT, para uma situação que vale além do estado fundamental. Este foi o trabalho feito por Runge e Gross (RG), que mostraram que se pode estabelecer uma relação entre a densidade dependente do tempo $\rho(r, t)$ e o potencial externo dependente do tempo $v(r, t)$ [44] [46]. Isto é a Teoria do Funcional da Densidade Dependente do Tempo (TD-DFT) [47].

\subsection{O funcional híbrido CAM-B3LYP}

Devido ao baixo custo computacional e por obter uma boa descrição para as propriedades eletrônicas de sistemas moleculares, o funcional híbrido B3LYP [44] [45] é um dos funcionais mais conhecidos e utilizados atualmente. Para este funcional, a energia de troca $E_{x c}[\rho]$ possui $20 \%$ de Hartree-Fock $(\mathrm{HF}), 80 \%$ da Aproximação de Densidade Local de Spin (LSDA) e também uma contribuição proveniente do B88 [44]. Ainda há alguns termos para a correlação, que seriam 81\% de LYP [48] e 19\% de VWN (Vosko, Wilk e Nussair) [49].

Porém o funcional B3LYP não descreve muito bem algumas situações, tais como: $(i)$ 
polarizabilidade para cadeias longas, (ii) algumas excitações usando TD-DFT [50] [51] [52] para estados de Rydberg, (iii) excitações que envolvam transferência de carga [53] [54] [55], o que seria o caso mais importante. A razão para estas falhas do funcional híbrido B3LYP é devido ao fato de que para longo alcance o potencial de troca possui uma dependência como $-0.2 r^{-1}$, ao invés do valor exato que seria $-r^{-1}$.

Com isso, um novo funcional híbrido de troca e correlação foi proposto, sendo chamado de CAM-B3LYP [56]. Este funcional busca combinar qualidades do funcional B3LYP e correções de longo alcance. Inicialmente, Tawada et al. [57] haviam proposto a seguinte relação para corrigir as deficiências do funcional B3LYP, na qual dividem o termo $r_{12}^{-1}$ em duas partes

$$
\frac{1}{r_{12}}=\frac{1-\operatorname{erf}\left(\mu r_{12}\right)}{r_{12}}+\frac{\operatorname{erf}\left(\mu r_{12}\right)}{r_{12}}
$$

onde o primeiro termo descreve interações de curto alcance e o segundo termo descreve interações de longo alcance. O objetivo era verificar como estudos utilizando DFT podiam ser realizados com uma precisão adequada para os casos de polarizabilidade de cadeias longas, estados excitados de Rydberg e excitações que envolvessem transferência de carga.

Foi preciso generalizar a forma da equação (3.38) utilizando-se de dois parâmetros extras $\alpha$ e $\beta[56]$

$$
\frac{1}{r_{12}}=\frac{1-\left[\alpha+\beta \cdot \operatorname{erf}\left(\mu r_{12}\right)\right]}{r_{12}}+\frac{\alpha+\beta \cdot \operatorname{erf}\left(\mu r_{12}\right)}{r_{12}}
$$

É necessário que sejam satisfeitas as relações: $(i) 0 \leq \alpha+\beta \leq 1$, (ii) $0 \leq \alpha \leq 1$ e (iii) $0 \leq \beta \leq 1$. Essa abordagem foi chamada de método de Atenuação de Coulomb (CAM - Coulomb-attenuating method). O parâmetro $\alpha$ permite incorporar as contribuições de Hartree-Fock (HF) e o parâmetro $\beta$ permite incorporar o homólogo à DFT, através de um fator $1-(\alpha+\beta)$. Para o caso B3LYP, teremos $\alpha=0.2$ e $\beta=0$. A questão de 
se utilizar dois parâmetros extras $(\alpha$ e $\beta)$ fornece uma maior flexibilidade e um maior entendimento do quanto a contribuição de troca $(\mathrm{HF})$ é importante para regiões de curto alcance e a DFT é importante para regiões de longo alcance.

No trabalho proposto por Yanai et al. [56] buscou-se utilizar alguns pontos do funcional B3LYP, no que se refere as qualidades obtidas para o valor da energia e também utilizar a característica assintótica para as correções de longo alcance (LC). O funcional CAM-B3LYP compreende 19\% de Hartree-Fock somado a $81 \%$ proveniente do B88-Becke(1988), para o caso de interações de curto alcance. Para regiões de longo alcance temos $65 \%$ de $\mathrm{HF}$ e $35 \%$ de B 88 .

É conhecido que excitações do tipo $n \rightarrow \pi^{*}$, entre partes de um mesmo fragmento de um sistema molecular, são bem reproduzidas por todos os métodos de DFT quando comparados com o método altamente eficiente CASPT2 (método de multiconfiguracional de Mecânica Quântica Molecular, com pertubações de segunda ordem, do inglês Complete Active Space Perturbation Theory [58]). Porém, para sistemas excitados que envolvem transferências de carga $\left(n \rightarrow \pi^{*}\right.$ e $\left.\pi \rightarrow \pi^{*}\right)$ entre diferentes fragmentos, cálculos de DFT utilizando-se de funcionais como o BLYP ou B3LYP, não alcançam bons resultados (para o caso $n \rightarrow \pi^{*}$, BLYP fica muito abaixo de $3.3 \mathrm{eV}$ do que CASPT2 e B3LYP também fica $1.7 \mathrm{eV}$ abaixo do que CASPT2). No caso de excitações do tipo $\pi \rightarrow \pi^{*}$, todos os métodos de DFT obtém valores superestimados. Com os parâmetros $\alpha=0.19$ e $\alpha+\beta=0.65$ [56], obteve-se um bom resultado quando comparado ao CASPT2. Os estudos para sistemas que apresentam transferência de carga, utilizando-se do funcional CAM-B3LYP, mostraram uma boa precisão $(0.1 \mathrm{eV})$ se comparado ao CASPT2. O funcional CAM-B3LYP também apresenta uma boa precisão com os valores obtidos para a energia, se comparado ao funcional B3LYP. Em termos de implementação computacional, CAM-B3LYP possui um maior custo.

Nesta dissertação utilizou-se o funcional CAM-B3LYP para cálculo das propriedades 
eletrônicas do sistema pNA em $\mathrm{CO}_{2}$ supercrítico, justamente pelo fato desse sistema apresentar transferência de carga. 



\section{Resultados}

Neste capítulo iremos estudar o espectro de absorção da paranitroanilina (pNA) em fluido supercrítico, sendo o $\mathrm{CO}_{2}$ supercrítico utilizado como solvente. Com base em considerações físico-químicas e estudos anteriores, iremos propor e verificar 3 casos de campos de força para o $\mathrm{CO}_{2}$ supercrítico e por fim será feito uma proposta de alteração da geometria da $p N A$.

\subsection{Análise dos potenciais clássicos}

$\mathrm{O} \mathrm{CO}_{2}$ supercrítico pode ser considerado como uma "alternativa verde" para os solventes orgânicos convencionais, os quais geralmente são tóxicos e nocivos ao meio ambiente. A busca por solventes mais seguros e a crescente consciência sobre a questão ambiental, tem levado a uma "química verde" (green chemistry) [61] [62] no sentido de se buscar soluções sustentáveis. Além disso, o $\mathrm{CO}_{2}$ supercrítico é um sistema molecular triatômico simples, de baixo custo, não tóxico, não inflamável e de fácil obtenção e reciclagem. Tais qualidades fazem com que seja muito utilizado em segmentos industriais e laboratoriais da química, biologia e farmácia, como um solvente benigno ao meio ambiente [63].

O $\mathrm{CO}_{2}$ supercrítico possui uma pressão crítica de 72,79 atm e temperatura crítica de $304,1 \mathrm{~K}\left(31^{\circ} \mathrm{C}\right)$, que é um valor de fácil obtenção. Estes fatores fazem com que o $\mathrm{CO}_{2}$ supercrítico seja um solvente muito utilizado em separações biomoleculares e aplicações farmacêuticas [68]. Este estado supercrítico garante uma "ponte" entre o estado líquido 
e gasoso, já que pode oferecer uma característica do estado gasoso (como taxas de difusão, por exemplo) e do estado líquido (densidades de solvente). Por isso pode ser usado como um meio de reação e de separação. Algumas referências que tratam sobre o $\mathrm{CO}_{2}$ supercrítico e fluidos supercríticos de maneira geral são encontradas em [61] [62] [63] [64] [65] [66] [67].

Neste trabalho inicialmente será feito a verificação e validação de campos de força tradicionais, aplicados na região supercrítica para o $\mathrm{CO}_{2}$. Consideramos três modelos de campos de força para o $\mathrm{CO}_{2}$ supercrítico, para estudar as propriedades estruturais e eletrônicas. No caso 1, utilizamos os valores das cargas e os parâmetros $\epsilon$ e $\sigma$ presentes na referência Zhang e Duan - An Optimized Molecular Potential for Carbon Dioxide [11] , que reproduzem bem os valores experimentais do ponto crítico do $\mathrm{CO}_{2}$, propriedades estruturais e outras propriedades termodinâmicas como curvas de coexistência líquido-vapor. Para o caso 2, apenas alteramos os valores das cargas do $\mathrm{CO}_{2}$, utilizando agora os valores de cargas presentes na referência [59]. Tanto o primeiro quanto o segundo caso, consideram a geometria do $\mathrm{CO}_{2}$ de forma linear.

A referência [59] (Polar attributes of supercritical carbon dioxide), usada no segundo caso, traz um estudo sobre as características apolares do $\mathrm{CO}_{2}$ e suas relações com a solvatação. Historicamente o $\mathrm{CO}_{2}$ foi tratado como um solvente apolar, inicialmente devido sua baixa constante dielétrica e também por seu momento de dipolo ser igual a zero. Mas também foi descrito como um solvente quadrupolar, devido seu momento de quadrupolo. Nesta referência é citado o fato de que apesar da larga utilização do $\mathrm{CO}_{2}$ supercrítico como solvente, ainda há uma certa falta de entendimento a nível molecular (microscópico) do fenômeno de solvatação do $\mathrm{CO}_{2}$. São feitos alguns questionamentos, como por exemplo, como o $\mathrm{CO}_{2}$ é classificado como solvente? Ou quais sistemas moleculares ordenados são dissolvidos em $\mathrm{CO}_{2}$ ? Apesar de apresentar momento de dipolo igual a zero, a molécula de $\mathrm{CO}_{2}$ possui uma certa separação de cargas o que 
resulta num momento de quadrupolo e com isto o $\mathrm{CO}_{2}$ pode ser descrito como um solvente quadrupolar [69] [70]. Estudos recentes sugerem que quanto mais se analisa o comportamento microscópico do solvente $\mathrm{CO}_{2}$, percebe-se que ele pode atuar como um ácido de Lewis fraco ou como uma base de Lewis [60] .

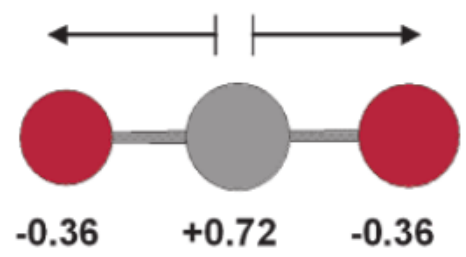

Figura 4.1: Cargas do $\mathrm{CO}_{2}$. Figura extraída da referência [59].

No caso 3, mantivemos os mesmos parâmetros do caso 2, mas desta vez alteramos a geometria do $\mathrm{CO}_{2}$, considerando um ângulo $\theta_{O-C-O}=176^{\circ}$ e a distância $R_{C O}=1.18 \AA$, conforme obtido em uma dinâmica molecular de Born-Oppenheimer [5]. Um trabalho anterior de D. Truhlar com Dinâmica Molecular [81] também havia proposto esse ângulo.

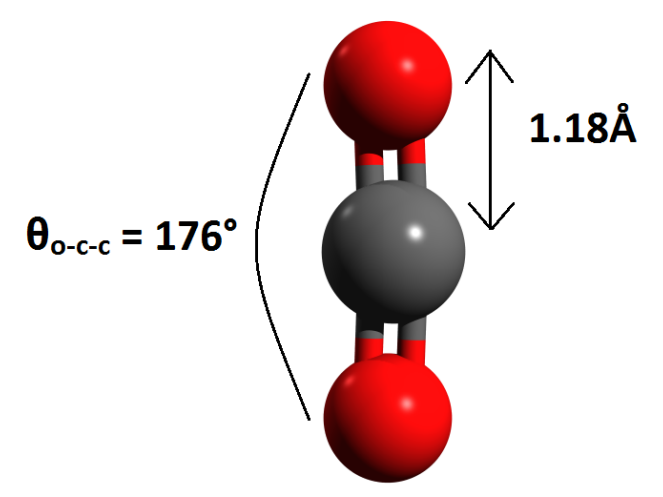

Figura 4.2: Caso $3-\mathrm{CO}_{2}$ não linear

Nas tabelas seguintes, estão representados os 3 casos citados. 
Tabela 4.1: Caso 1: $\mathrm{CO}_{2}$ homogêneo e linear usando os parâmetros $\epsilon, \sigma$, geometria e carga de Zhang e Duan [11].

\begin{tabular}{ccccccc}
\hline \hline & \multicolumn{2}{c}{ Coordenadas Cartesianas } & Carga & \multicolumn{2}{c}{ Parâmetros OPLS } \\
\hline Átomo & $\mathrm{x}(\AA)$ & $\mathrm{y}(\AA)$ & $\mathrm{z}(\AA)$ & $q(e)$ & $\epsilon(k c a l / m o l)$ & $\sigma(\AA)$ \\
\hline $\mathrm{C}$ & 0.000 & 0.000 & 0.000 & 0.5888 & 0.057 & 2.7918 \\
$\mathrm{O}$ & 0.000 & 0.000 & 1.163 & -0.2944 & 0.164 & 3.0000 \\
$\mathrm{O}$ & 0.000 & 0.000 & -1.163 & -0.2944 & 0.164 & 3.0000 \\
\hline
\end{tabular}

Tabela 4.2: Caso 2: $\mathrm{CO}_{2}$ homogêneo e linear usando os parâmetros $\epsilon, \sigma$ e geometria de Zhang e Duan [11]. As cargas foram usadas do Acc. Chem. Res. 2005, 38, 478-485 [59].

\begin{tabular}{ccccccc}
\hline \hline & \multicolumn{2}{c}{ Coordenadas Cartesianas } & Carga & \multicolumn{2}{c}{ Parâmetros OPLS } \\
\hline Átomo & $\mathrm{x}(\AA)$ & $\mathrm{y}(\AA)$ & $\mathrm{z}(\AA)$ & $q(e)$ & $\epsilon(k c a l / m o l)$ & $\sigma(\AA)$ \\
\hline $\mathrm{C}$ & 0.000 & 0.000 & 0.000 & 0.7200 & 0.057 & 2.7918 \\
$\mathrm{O}$ & 0.000 & 0.000 & 1.163 & -0.3600 & 0.164 & 3.0000 \\
$\mathrm{O}$ & 0.000 & 0.000 & -1.163 & -0.3600 & 0.164 & 3.0000 \\
\hline
\end{tabular}

Tabela 4.3: Caso 3: $\mathrm{CO}_{2}$ homogêneo e não linear usando os parâmetros $\epsilon, \sigma$ e geometria de Zhang e Duan [11] . As cargas foram usadas do Acc. Chem. Res. 2005, 38, 478-485 [59]. Consideramos $\theta_{O-C-O}=176^{\circ}$.

\begin{tabular}{ccccccc}
\hline \hline & \multicolumn{2}{c}{ Coordenadas Cartesianas } & Carga & \multicolumn{2}{c}{ Parâmetros OPLS } \\
\hline Átomo & $\mathrm{x}(\AA)$ & $\mathrm{y}(\AA)$ & $\mathrm{z}(\AA)$ & $q(e)$ & $\epsilon(k c a l / m o l)$ & $\sigma(\AA)$ \\
\hline $\mathrm{C}$ & 0.000 & 0.000 & 0.000 & 0.7200 & 0.057 & 2.7918 \\
$\mathrm{O}$ & 0.041 & 0.000 & 1.179 & -0.3600 & 0.164 & 3.0000 \\
$\mathrm{O}$ & 0.041 & 0.000 & -1.179 & -0.3600 & 0.164 & 3.0000 \\
\hline
\end{tabular}

Utilizando o programa DICE [27], foi feita uma simulação clássica para cada um destes casos. Inicialmente consideramos o sistema homogêneo contendo apenas $\mathrm{CO}_{2}$ (1001 moléculas). No ensemble NVT, a etapa de termalização levou $5 \times 10^{7}$ passos de MC e na etapa de equilíbrio e cálculo das propriedades desejadas, considerou-se $1 \times 10^{8}$ passos de MC. Todas as simulações foram feitas considerando a condição supercrítica para o $\mathrm{CO}_{2}$, ou seja, $T_{c}=315 \mathrm{~K}$ e densidade $\rho=0.81 \mathrm{~g} / \mathrm{cm}^{3}$. As funções de distribuição 
radial de pares $G(r)$ mostradas abaixo, nos informam como se dá a distribuição das moléculas.

$(\mathrm{C}-\mathrm{C})$

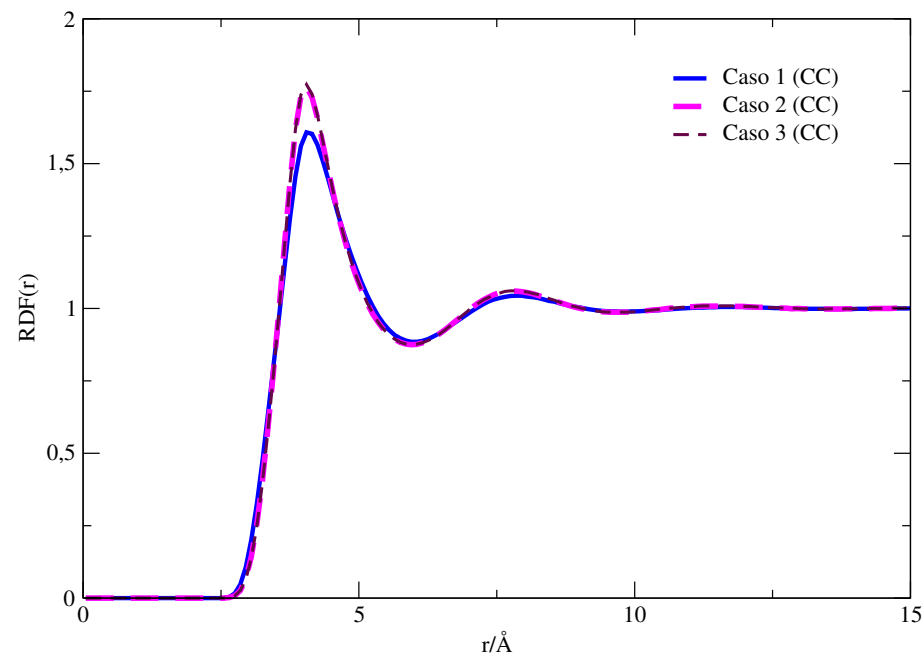

Figura 4.3: Funções de distribuição radial (RDF's) - Casos 1, 2 e 3 para os átomos Carbono - Carbono.

$(\mathrm{C}-\mathrm{O})$

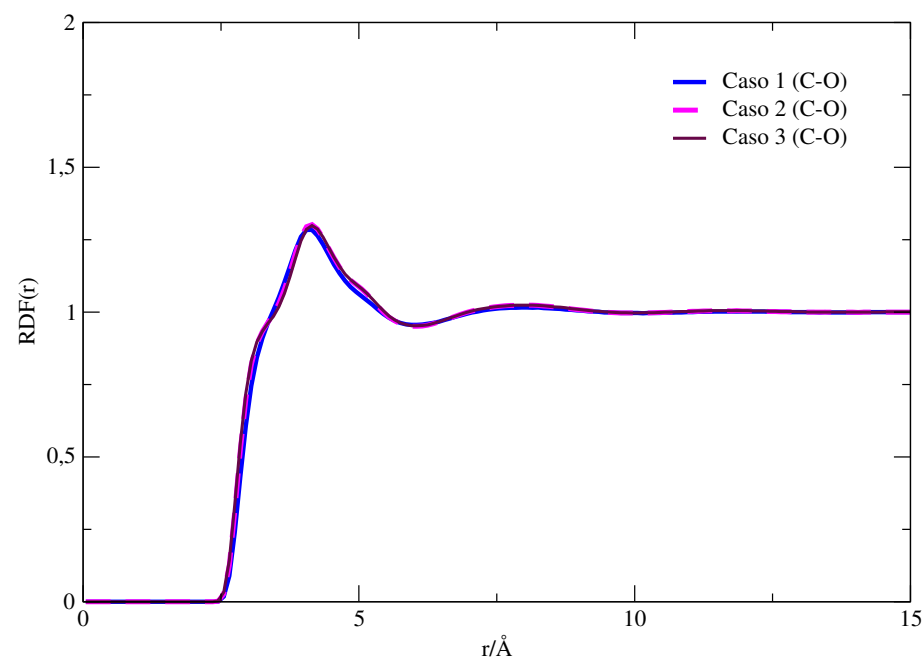

Figura 4.4: Funções de distribuição radial (RDF's) - Casos 1, 2 e 3 para os átomos Carbono - Oxigênio. 


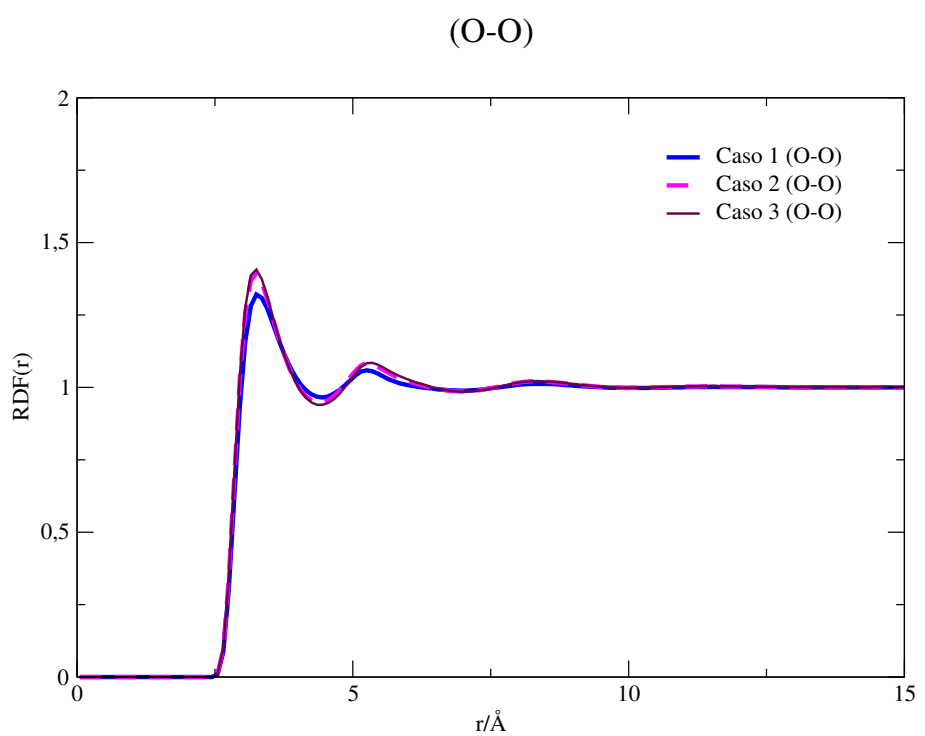

Figura 4.5: Funções de distribuição radial (RDF's) - Casos 1, 2 e 3 para os átomos Oxigênio - Oxigênio.

Na tabela seguinte resumimos os valores obtidos para o número de vizinhos aos atómos de carbono e oxigênio de cada um dos casos citados. Sendo $r(\AA)$ a distância onde termina o primeiro pico bem definido nos gráficos acima, $G(r)$ o valor correspondente à função de distribuição radial e $N(r)$ o número vizinhos. 
Tabela 4.4: Resumo dos valores obtidos para os casos 1, 2 e 3.

\begin{tabular}{cccc}
\hline \hline \multicolumn{4}{c}{ CASO 1 $(\langle\mu\rangle=0.00 D)$} \\
\hline Átomos analisados & $r(\AA)$ & $G(r)$ & $N(r)$ \\
\hline C-C & 6.05 & 0.89 & 10 \\
C-O & 5,95 & 0.96 & 9 \\
O-O & 4.45 & 0.97 & 3 \\
\hline \hline
\end{tabular}

\begin{tabular}{cccc}
\hline \hline \multicolumn{4}{c}{ CASO 2 $(\langle\mu\rangle=0.00 D)$} \\
\hline Átomos analisados & $r(\AA)$ & $G(r)$ & $N(r)$ \\
\hline C-C & 5.95 & 0.88 & 10 \\
C-O & 6.05 & 0.95 & 10 \\
O-O & 4.45 & 0.95 & 4 \\
\hline \hline
\end{tabular}

\begin{tabular}{cccc}
\hline \hline \multicolumn{4}{c}{ CASO 3 $(\langle\mu\rangle=0.14 D)$} \\
\hline Átomos analisados & $r(\AA)$ & $G(r)$ & $N(r)$ \\
\hline C-C & 5.95 & 0.88 & 10 \\
C-O & 6.05 & 0.95 & 10 \\
O-O & 4.45 & 0.94 & 4 \\
\hline \hline
\end{tabular}

\subsection{A estrutura da pNA em Fluido Supercrítico $\mathrm{CO}_{2}$}

A paranitroanilina (pNA) [75] [76] [77] [78] [79] [80] possui uma estrutura simples, composta de um grupo amina $\left(\mathrm{NH}_{2}\right)$, um anel benzênico e um grupo nitro $\left(\mathrm{NO}_{2}\right)$. O grupo amina pode ser considerado como um doador de elétrons e o grupo nitro como um aceitador de elétrons.

Inicialmente a geometria da pNA foi otimizada considerando teoria de pertubação de segunda ordem (MP2) e a base aug-cc-pVDZ, usando o programa Gaussian 09 [74]. Com o modelo PCM, utilizamos o valor de $\epsilon=1.5$ para a constante dielétrica [71]. Usamos essa geometria para os cálculos com $\mathrm{CO}_{2}$ supercrítico. 


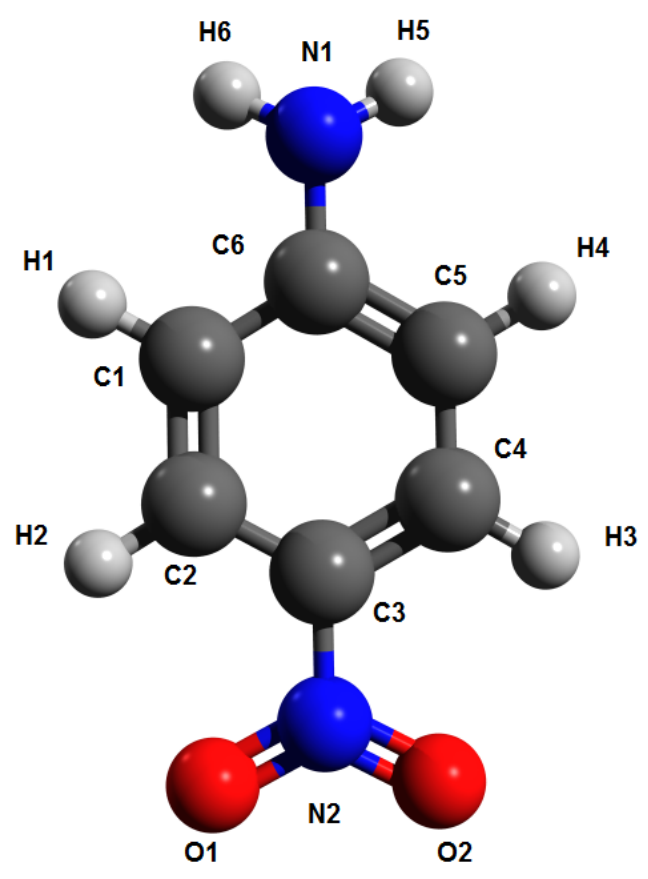

Figura 4.6: Geometria otimizada da pNA utilizando MP2/aug-cc-pVDZ. O valor da constante dielétrica usado foi de $\epsilon=1.5$ [71].

As cargas atômicas da pNA foram calculadas considerando uma situação isolada e uma situação em solvente usando o modelo PCM, com ajuste CHELPG (usando o mesmo valor de constante dielétrica $\epsilon=1.5$ ). Nota-se uma polarização pequena aumentando o momento de dipolo da pNA por cerca de $9 \%$. 
Tabela 4.5: Estudo das cargas atômicas da pNA isolada e polarizada. Também está indicado o momento de dipolo (em Debye).

\begin{tabular}{ccc}
\hline \hline Átomo & PCM $(\epsilon=1.5)$ & Isolada \\
\hline C1 & -0.128370 & -0.123193 \\
C2 & -0.230961 & -0.223699 \\
C3 & 0.154041 & 0.153584 \\
C4 & -0.232004 & -0.224722 \\
C5 & -0.127310 & -0.122141 \\
C6 & 0.288305 & 0.272804 \\
N1 & -0.749465 & -0.721556 \\
N2 & 0.565904 & 0.552988 \\
O1 & -0.390616 & -0.374832 \\
O2 & -0.390389 & -0.374588 \\
H1 & 0.137412 & 0.131024 \\
H2 & 0.154742 & 0.148578 \\
H3 & 0.154881 & 0.148704 \\
H4 & 0.137261 & 0.130879 \\
H5 & 0.328288 & 0.313067 \\
H6 & 0.328282 & 0.313103 \\
$\mu(D)$ & 6.7974 & 6.2348 \\
\hline \hline
\end{tabular}

Os parâmetros do campo de força da pNA, utilizados nas simulações com o $\mathrm{CO}_{2}$ supercrítico, são indicados na tabela 4.6 abaixo. 
Tabela 4.6: Coordenadas otimizadas, cargas atômicas (em unidades atômicas) e parâmetros do campo de força da pNA [82] [83], utlizados na simulação com o $\mathrm{scCO}_{2}$.

\begin{tabular}{ccccccc}
\hline \hline Átomo & $\mathrm{x}(\AA)$ & $\mathrm{y}(\AA)$ & $\mathrm{z}(\AA)$ & $q(e)$ & $\epsilon(k c a l / m o l)$ & $\sigma(\AA)$ \\
\hline $\mathrm{C} 1$ & -1.3729 & 1.2174 & -0.0045 & -0.1283 & 0.0700 & 3.5500 \\
$\mathrm{C} 2$ & 0.0277 & 1.2255 & -0.0028 & -0.2309 & 0.0700 & 3.5500 \\
$\mathrm{C} 3$ & 0.7117 & 0.0000 & -0.0014 & 0.1540 & 0.0700 & 3.5500 \\
$\mathrm{C} 4$ & 0.0277 & -1.2255 & -0.0015 & -0.2320 & 0.0700 & 3.5500 \\
$\mathrm{C} 5$ & -1.3729 & -1.2174 & -0.0034 & -0.1273 & 0.0700 & 3.5500 \\
$\mathrm{C} 6$ & -2.0938 & 0.0000 & -0.0021 & 0.2883 & 0.0700 & 3.5500 \\
$\mathrm{~N} 1$ & -3.4895 & -0.0001 & -0.0726 & -0.7493 & 0.1200 & 3.2960 \\
$\mathrm{~N} 2$ & 2.1789 & 0.0000 & 0.0026 & 0.5659 & 0.1200 & 3.2500 \\
$\mathrm{O} 1$ & 2.7597 & 1.0967 & 0.0058 & -0.3906 & 0.1700 & 2.9600 \\
$\mathrm{O} 2$ & 2.7597 & -1.0967 & 0.0026 & -0.3903 & 0.1700 & 2.9600 \\
$\mathrm{H} 1$ & -1.9172 & 2.1680 & -0.0107 & 0.1374 & 0.0300 & 2.4200 \\
$\mathrm{H} 2$ & 0.5868 & 2.1634 & -0.0016 & 0.1547 & 0.0300 & 2.4200 \\
$\mathrm{H} 3$ & 0.5867 & -2.1634 & 0.0004 & 0.1548 & 0.0300 & 2.4200 \\
$\mathrm{H} 4$ & -1.9173 & -2.1679 & -0.0088 & 0.1372 & 0.0300 & 2.4200 \\
$\mathrm{H} 5$ & -3.9431 & -0.8425 & 0.2713 & 0.3282 & 0.0000 & 0.0000 \\
$\mathrm{H} 6$ & -3.9431 & 0.8436 & 0.2677 & 0.3282 & 0.0000 & 0.0000 \\
\hline \hline
\end{tabular}

Uma última proposta foi adotada, incluindo uma mudança estrutural da pNA [72]. Na geometria inicial a distância $\mathrm{d}(\mathrm{C}-\mathrm{N})$ do grupo amina $\left(\mathrm{NH}_{2}\right)$ é de $1.397 \AA$, mas passou a ser $1.386 \AA$. A distância $\mathrm{d}(\mathrm{C}-\mathrm{N})$ do grupo nitro $\left(\mathrm{NO}_{2}\right)$ é de $1.467 \AA$, mas passou a ser $1.465 \AA$. A distância d(N-O) considerada foi de $1.25 \AA$, mas anteriormente essa distância era de $1.24 \AA$. 


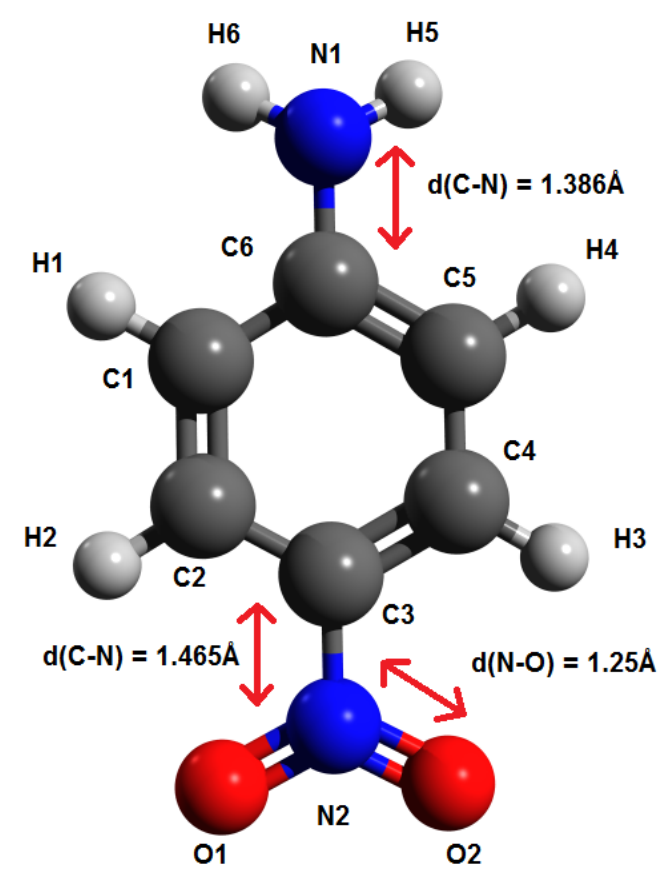

Figura 4.7: Geometria modificada da pNA

\subsection{O Espectro de absorção da pNA em Fluido Supercrítico $\mathrm{CO}_{2}$}

\subsubsection{Simulação clássica de MC da pNA em Fluido Supercrítico $\mathrm{CO}_{2}$}

Através do programa DICE [27], foram feitas três simulações de Monte Carlo (MC) envolvendo uma molécula de pNA e 1000 moléculas de $\mathrm{CO}_{2}$, para cada um dos casos citados anteriormente. Utilizamos uma temperatura de $315 K$ e densidade $\rho=$ $0.81 \mathrm{~g} / \mathrm{cm}^{3}$ no ensemble NVT, pois esta é a condição usada na medida experimental do espectro de absorção da pNA em $\mathrm{CO}_{2}$ supercrítico. Em cada simulação foram realizados um total de $1,2 \times 10^{8}$ passos MC na etapa de termalização e $3 \times 10^{8}$ passos MC na etapa de equilibrio. A geometria da pNA é sempre mantida fixa, na geometria 
de mínima energia (otimizada). De forma resumida, tratamos dos seguintes casos:

1: pNA $+\mathrm{CO}_{2}$ supercrítico do caso 1

2: pNA $+\mathrm{CO}_{2}$ supercrítico do caso 2 (no qual tivemos uma alteração das cargas)

3: pNA $+\mathrm{CO}_{2}$ supercrítico do caso 3 (caso em que tratamos o $\mathrm{CO}_{2}$ como não linear)

A função de distribuição de mínima distância (MDDF) entre a pNA e as moléculas de $\mathrm{CO}_{2}$ calculada durante a simulação, fornece o número de coordenação na primeira camada de solvatação em torno da pNA. Abaixo seguem as funções MDDF para os casos estudados. O número de coordenação para os três casos, obtido por meio da integração da curva sob o primeiro pico das funções de mínima distância (MDDF), foi de 18 moléculas de $\mathrm{CO}_{2}$ na primeira camada de solvatação para o caso 1 e 17 moléculas para os casos 2 e 3. Por fim foi realizado um último estudo, descrito como caso 4, mas agora considerando a geometria da pNA (conforme figura 4.7) obtida da simulação de Born-Oppenheimer [72]. Então fizemos uma simulação MC utilizando essa geometria modificada da pNA e o $\mathrm{CO}_{2}$ supercrítico não linear do caso 3. Neste caso obtivemos 16 moléculas na primeira camada de solvatação.

As funções MDDF ficaram: 


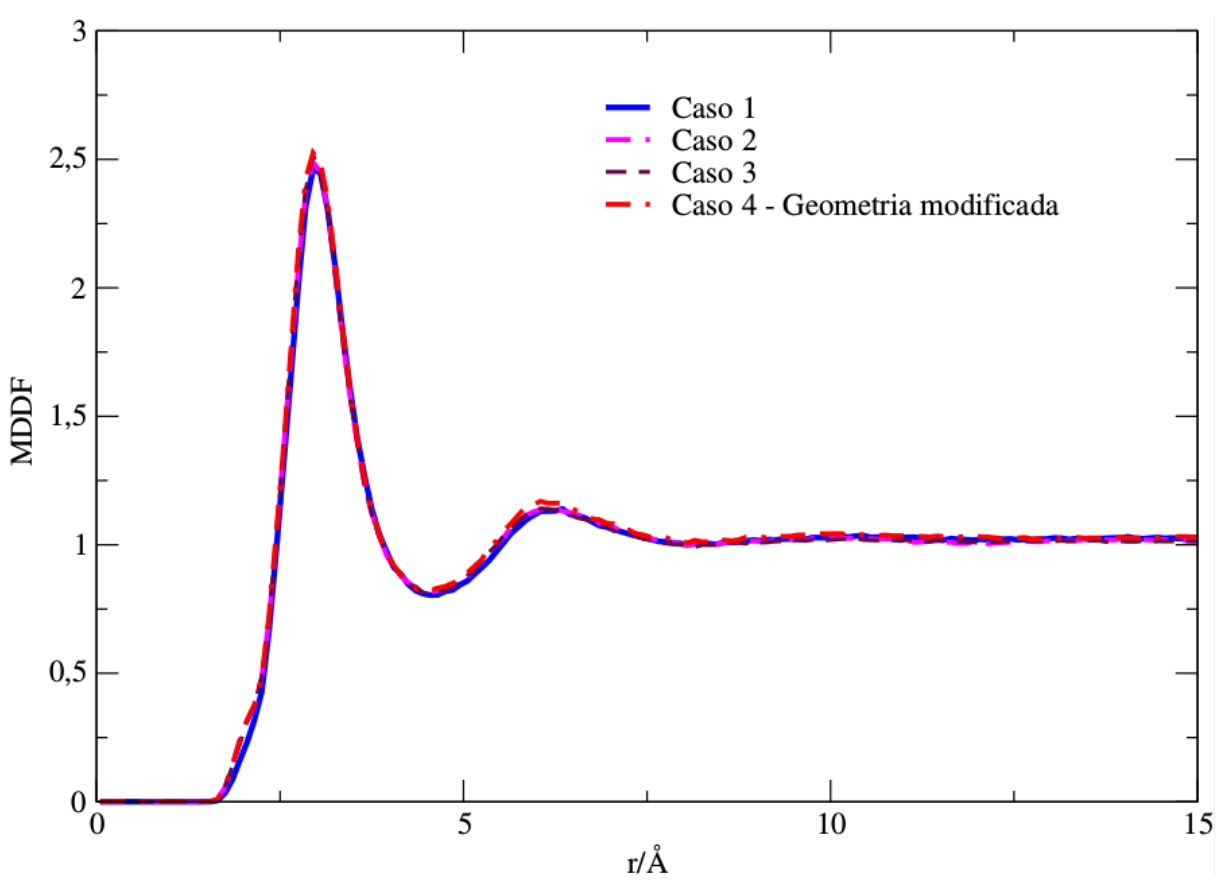

Figura 4.8: MDDF - Funções de mínima distância para os casos 1, 2, 3 e 4.

É importante ressaltar que as simulações que foram feitas para os todos os casos, tinham o intuito de verificar a influência de alguns pontos no sistema. Por exemplo, ao passarmos do caso 1 para o caso 2, estamos buscando verificar a contribuição eletrostática ao alteramos apenas as cargas do $\mathrm{CO}_{2}$ supercrítico. Já no caso 3, buscamos verificar a influência da geometria do sistema, uma vez que tratamos do caso em que o $\mathrm{CO}_{2}$ é não linear. No caso 4 , é verificado a influência da geometria da pNA.

\subsubsection{Cálculo do espectro eletrônico}

Os estados eletrônicos excitados da pNA foram calculados utilizando a Teoria do Funcional da Densidade Dependente do Tempo (TD-DFT) [47]. Utilizamos o funcional híbrido CAM-B3LYP, juntamente com a base aug-cc-pVDZ, para descrever o espectro de absorção da pNA em vácuo (isolada) e da pNA em meio solvente de $\mathrm{CO}_{2}$ 
supercrítico para cada um dos casos citados, com isso buscamos verificar os efeitos do $\mathrm{CO}_{2}$ supercrítico no espectro de absorção da pNA. Este funcional foi escolhido porque é muito recomendado para descrever excitações que envolvem transferências de carga, o que se enquadra no caso da pNA. Para a pNA, temos uma transferência de carga, sendo uma transição do tipo $\pi \rightarrow \pi^{*}$, ocorrendo entre os orbitais HOMO (Highest Occupied Molecular Orbital) e LUMO (Lowest Unoccupied Molecular Orbital).

A transferência de carga ocorre do $\mathrm{NH}_{2}$ (amina) para o $\mathrm{NO}_{2}$ (nitro).

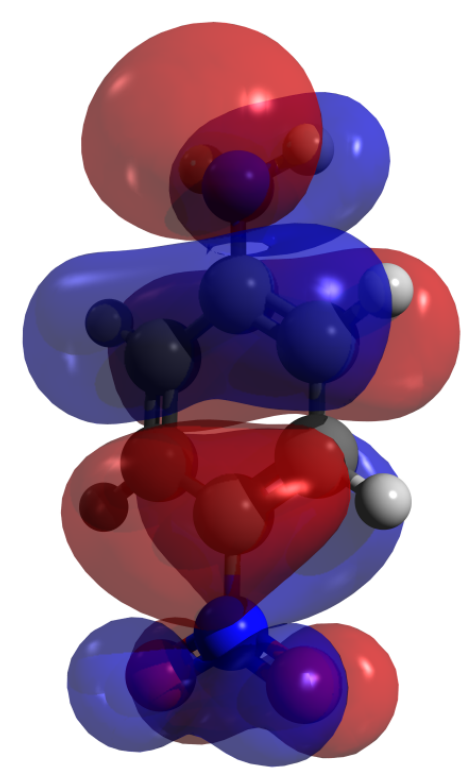

HOMO

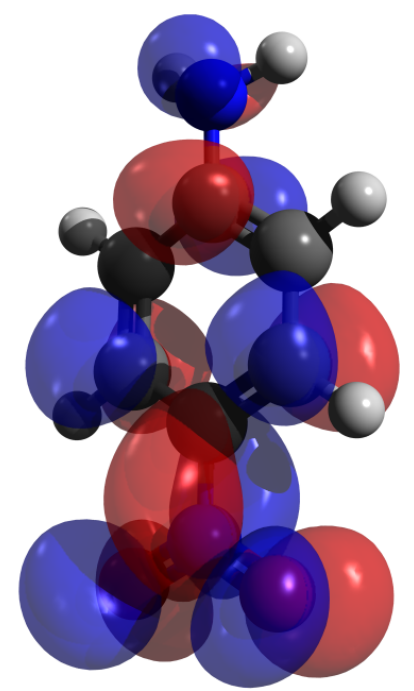

LUMO

Figura 4.9: Representação de um orbital molecular da pNA - transição $\pi \rightarrow \pi^{*}$ (HOMO - LUMO)

Após as simulações clássicas de MC, para cada caso foram separadas 100 configurações estatisticamente descorrelacionadas para com isso efetuar os cálculos de espectro eletrônico. Estes cálculos foram feitos de duas maneiras. Na primeira maneira, o efeito de solvente causado pelo $\mathrm{CO}_{2}$ foi incluído somente através da interação eletrostática (usando o solvente apenas como cargas pontuais nos sítios atômicos). Nesta 
situação consideramos 100 configurações compostas de 1 pNA + 350 moléculas de $\mathrm{CO}_{2}$, formando o embedding eletrostático. A segunda maneira considera novamente as 100 configurações, mas compostas de 1 molécula de pNA +12 moléculas de $\mathrm{CO}_{2}$ explícitas na primeira camada de solvatação +350 moléculas de $\mathrm{CO}_{2}$ apenas como cargas pontuais. Utilizamos 12 moléculas na primeira camada de solvatação e não 18 moléculas, por exemplo, devido a questão do alto custo computacional. Apenas como ilustração, na figura 4.2 temos uma representação de uma molécula de pNA + 12 moléculas de $\mathrm{CO}_{2}$ explicitamente na primeira camada de solvatação.

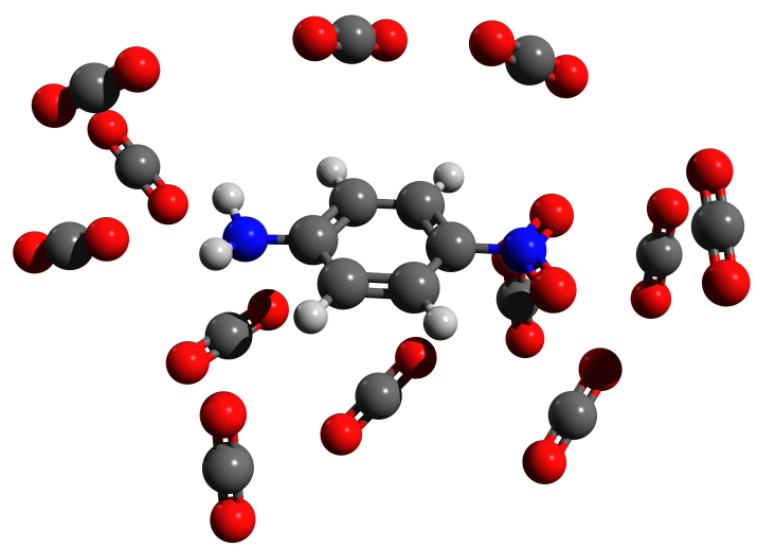

Figura 4.10: Exemplo de uma configuração incluindo parte da primeira camada de solvatação, considerando 1 molécula de pNA +12 moléculas de $s c \mathrm{CO}_{2}$

Os valores obtidos para as transições eletrônicas são descritos na tabela 4.7 abaixo. Obtivemos um valor de $4.31 \mathrm{eV}$ para a transição eletrônica da pNA isolada, que está próximo do valor experimental de $4.25 \mathrm{eV}$ [84]. Vemos que o shift (deslocamento) experimental é de $0.35 \mathrm{eV}$ entre a pNA isolada e em meio solvente $(4.25 \mathrm{eV} / \mathrm{em}$ vácuo - $3.90 \mathrm{eV} /$ em $\mathrm{CO}_{2}$ supercrítico [85]). Comparando agora os valores calculados com os valores experimentais, temos que:

1: $\underline{\text { pNA isolada e valor experimental }} \rightarrow$ shift de $0.06 \mathrm{eV}(4.31 \mathrm{eV}-4.25 \mathrm{eV})$;

2: pNA isolada e caso $1 \rightarrow$ shift de $0.09 \mathrm{eV}(4.31 \mathrm{eV}-4.22 \mathrm{eV})$ para o caso de cargas 
pontuais e shift de $0.18 \mathrm{eV}(4.31 \mathrm{eV}-4.13 \mathrm{eV})$ para o caso de moléculas explícitas.

3: $\underline{\text { pNA isolada e caso } 2} \rightarrow$ shift de $0.12 \mathrm{eV}(4.31 \mathrm{eV}-4.19 \mathrm{eV})$ para o caso de cargas pontuais e shift de $0.19 \mathrm{eV}(4.31 \mathrm{eV}-4.12 \mathrm{eV})$ para o caso de moléculas explícitas.

4: $\underline{\text { pNA isolada e caso } 3} \rightarrow$ shift de $0.13 \mathrm{eV}(4.31 \mathrm{eV}-4.18 \mathrm{eV})$ para o caso de cargas pontuais e shift de $0.21 \mathrm{eV}(4.31 \mathrm{eV}-4.10 \mathrm{eV})$ para o caso de moléculas explícitas.

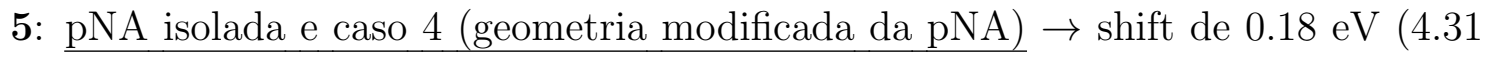
$\mathrm{eV}-4.13 \mathrm{eV})$ para o caso de cargas pontuais e shift de $0.26 \mathrm{eV}(4.31 \mathrm{eV}-4.05 \mathrm{eV})$ para o caso de moléculas explícitas.

Tabela 4.7: Valores obtidos para as transições eletrônicas. Na fase isolada (gasosa) utilizamos CAM-B3LYP/aug-cc-pVDZ. Para os casos pNA $+\mathrm{CO}_{2}$ supercrítico, também usamos CAM-B3LYP/aug-cc-pVDZ

\begin{tabular}{cccc}
\hline \hline & \multicolumn{3}{c}{ ISOLADA } \\
\hline \multirow{2}{*}{ Metodologia } & \multicolumn{3}{c}{ Transição em nm $(\mathrm{eV})$} \\
\cline { 2 - 4 } & Calculado & Experimental & Geom. Modificada da pNA \\
\hline Isolada & $288(4.31)$ & $292(4.25)$ & - \\
\hline \hline
\end{tabular}

\begin{tabular}{cccc}
\hline \hline & \multicolumn{2}{c}{ CASO 1 } \\
\hline \multirow{2}{*}{ Metodologia } & \multicolumn{3}{c}{ Transição em nm (eV) } \\
\cline { 2 - 4 } & Calculado & Experimental & Geom. Modificada da pNA \\
\hline pNA $+350 \mathrm{cp}$ & $294 \pm 3(4.22)$ & $318(3.90)$ & - \\
\hline pNA $+12 s c C O_{2}+350 \mathrm{cp}$ & $300 \pm 5(4.13)$ & $318(3.90)$ & - \\
\hline \hline
\end{tabular}

\begin{tabular}{cccc}
\hline \hline & \multicolumn{3}{c}{ CASO 2 } \\
\hline \multirow{2}{*}{ Metodologia } & \multicolumn{3}{c}{ Transição em nm (eV) } \\
\cline { 2 - 4 } & Calculado & Experimental & Geom. Modificada da pNA \\
\hline pNA $+350 \mathrm{cp}$ & $295 \pm 3(4.19)$ & $318(3.90)$ & - \\
\hline pNA $+12 s c C \mathrm{O}_{2}+350 \mathrm{cp}$ & $301 \pm 5(4.12)$ & $318(3.90)$ & - \\
\hline \hline
\end{tabular}

\begin{tabular}{cccc}
\hline \hline & CASO 3 & CASO 4 \\
\hline \multirow{2}{*}{ Metodologia } & \multicolumn{2}{c}{ Transição em nm (eV) } \\
\cline { 2 - 4 } & Calculado & Experimental & Geom. Modificada da pNA \\
\hline pNA $+350 \mathrm{cp}$ & $297 \pm 3(4.18)$ & $318(3.90)$ & $300 \pm 3(4.13)$ \\
\hline pNA $+12 s c C \mathrm{SO}_{2}+350 \mathrm{cp}$ & $302 \pm 5(4.10)$ & $318(3.90)$ & $306 \pm 5(4.05)$ \\
\hline \hline
\end{tabular}


Vemos que não há muita distinção entre os valores obtidos para os casos 1 e 2 . Com isso percebe-se que a alteração das cargas e consequente alteração da polarização do solvente, não possui muita influência na alteração do espectro de absorção da pNA. Também os valores obtidos considerando apenas cargas pontuais (modelo eletrostático), ficaram muito abaixo do shift experimental, pois temos o valor de 0.35 eV para o shift experimental enquanto que os valores calculados ficaram em torno de 0.09/0.12 eV para os casos 1 e 2 e 0.13 eV para o caso 3. Já nas situações em que foram consideradas moléculas explícitas, os valores obtidos nos casos 1 e 2 ficaram como metade do valor experimental. Ao se considerar o caso do $\mathrm{CO}_{2}$ não linear (caso 3) e moléculas explícitas, obtem-se um shift de $0.21 \mathrm{eV}$, que seria um valor bem melhor do que os valores obtidos no caso 1 e 2 . Assim é possível dizer que embora ainda diferindo do valor experimental de $0.14 \mathrm{eV}(0.35 \mathrm{eV}-0.21 \mathrm{eV})$, considerar as moléculas como explícitas dá uma melhor avaliação para o deslocamento espectral da pNA. No caso de cargas pontuais são consideradas apenas as contribuições eletrostáticas, enquanto que no caso de moléculas explícitas mais efeitos são previstos nas interações entre o soluto e solvente, por exemplo as interações de Van der Waals.

Contudo, vemos que os valores mais significativos são os valores obtidos no caso 4, no qual foi feita a alteração de geometria da pNA. Estas alterações são obtidas de um estudo anterior [72] usando-se BOMD, nas mesmas condições termodinâmicas. A mudança na geometria da pNA é decorrente da interação com o solvente. Com isto obteve-se o valor de $4.25 \mathrm{eV}$ para a energia de absorção no caso da pNA isolada e 4.05 eV considerando moléculas explicitas. Portanto, parte da banda de absorção vem da mudança estrutural. Usando as moléculas explícitas, obtemos um shift de $0.26 \mathrm{eV}$ (4.31 eV - $4.05 \mathrm{eV})$, um valor mais próximo do shift experimental.

Na tabela seguinte, fizemos um resumo no qual estão indicados os valores das ener- 
gias de excitação (em eV) e a força de oscilador (entre parêntesis) para todos os casos estudados.

Tabela 4.8: Transições eletrônicas calculadas $(\mathrm{eV})$ e as forças de oscilador (entre parêntesis) para a pNA em solvente $\mathrm{CO}_{2}$ supercrítico. Estes valores são valores médios das 100 configurações em que consideramos as 12 moléculas explícitas na primeira camada de solvatação. Os cálculos foram feitos utilizando-se o funcional CAM-B3LYP.

Transição Caso 01 Caso 02 Caso 03 Caso 04

\begin{tabular}{ccccc}
\hline$S_{0}-S_{1}$ & $3.89(0.00)$ & $3.90(0.00)$ & $3.91(0.00)$ & $3.84(0.00)$ \\
\hline$S_{0}-S_{2}$ & $4.13(0.37)$ & $4.12(0.37)$ & $4.10(0.37)$ & $4.05(0.38)$ \\
\hline$S_{0}-S_{3}$ & $4.42(0.00)$ & $4.43(0.00)$ & $4.43(0.00)$ & $4.34(0.00)$ \\
\hline
\end{tabular}

Uma vez que os valores obtidos são médias das 100 configurações estatisticamente descorrelacionadas e formam um espectro inomogêneo, buscamos também construir um espectro de absorção teórico, através da convolução das energias de transição e intensidades. Na figura abaixo, temos a convolução do espectro da pNA com geometria modificada em $\mathrm{CO}_{2}$ supercrítico. A convolução (linha contínua) tem máximo em 305 nm, que é igual ao valor médio. A banda em $305 \mathrm{~nm}$ é formada essencialmente pela excitação $S_{0}-S_{2}$. Vemos que o aparecimento de transições $S_{0}-S_{1}$ contribuiria para o red shift, o que não se obtém calculando as médias. 


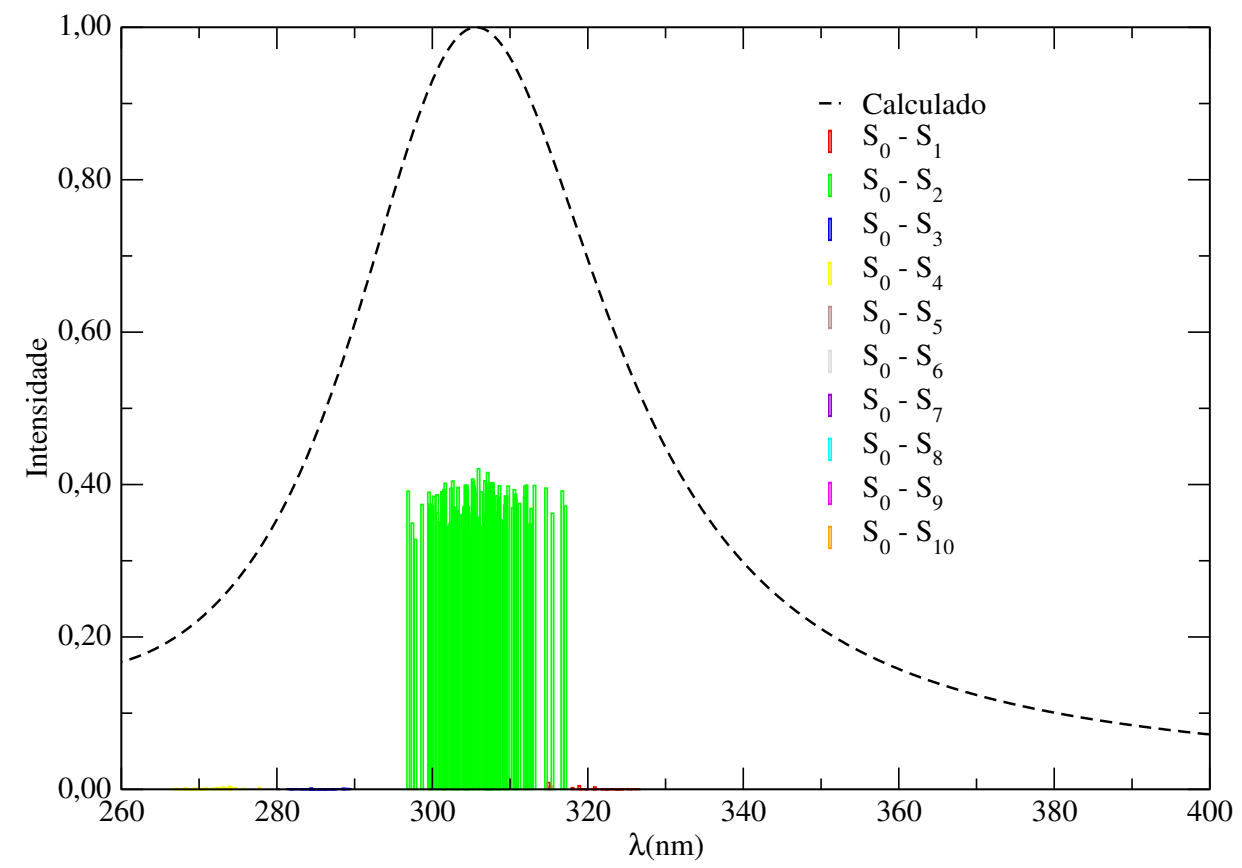

Figura 4.11: Convolução do espectro da pNA (geometria modificada) em $\mathrm{CO}_{2}$ supercrítico não linear, sendo considerado Intensidade em função do comprimento de onda. 



\section{Conclusões e Perspectivas}

Este capítulo apresenta nossas conclusões com base nos resultados obtidos deste trabalho. Ao final, apresentamos algumas perspectivas para projetos futuros.

Utilizando a metodologia S-QM/MM, na qual usamos simulações clássicas (MC) e cálculos quânticos, estudamos o espectro de absorção da paranitroanilina em $\mathrm{CO}_{2}$ supercrítico. Iniciamos o trabalho com uma análise e validação de 3 campos de força para o $\mathrm{CO}_{2}$ supercrítico, descritos como casos 1,2 e 3 . No caso 1 tomamos os valores das cargas e os parâmetros $\epsilon$ e $\sigma$ presentes na referência Zhang e Duan - An Optimized Molecular Potential for Carbon Dioxide [11]. Analisamos em seguida uma situação em que houve alteração de cargas (caso 2) e uma outra situação considerando uma mudança estrutural (caso 3$)$, que seria um caso não linear para o $\mathrm{CO}_{2}\left(\theta_{O-C-O}=\right.$ $176^{\circ}$ ). Partindo de uma geometria otimizada para a pNA, fizemos simulações clássicas e cálculos quânticos tomando a pNA como soluto e como solvente os 3 casos para o $\mathrm{CO}_{2}$ supercrítico. Os cálculos quânticos foram feitos utilizando o funcional CAM-B3LYP, por ser mais adequado para excitações que envolvem transferências de carga.

Não obtivemos valores muito distintos entre os casos 1 e 2 , em que houve apenas a alteração das cargas. Portanto, a alteração de cargas não é muito importante. Dado que o shift experimental para a banda de absorção da pNA isolada e em meio solvente é de $0.35 \mathrm{eV}$, nossos valores obtidos nestes casos ficaram em torno da metade do valor experimental (obtivemos valores de $0.18 \mathrm{eV}$ para o caso 1 e $0.19 \mathrm{eV}$ para o caso 2), considerando moléculas explícitas para representar o solvente. No caso 3, para o $\mathrm{CO}_{2}$ 
não linear, obtivemos valores um pouco mais próximos do experimental (0.21 eV para o shift).

Testamos por fim uma última situação na qual utilizamos uma geometria modificada da pNA, obtida de uma dinâmica de BOMD [72] da pNA interagindo com o solvente nas mesmas condições de fluido supercrítico. Nesta geometria são alteradas, com respeito à geometria da pNA isolada, as distâncias d(C-N) do grupo amina, d(C-N) do grupo nitro e d(N-O). Essa geometria modificada da pNA foi utilizada tratando o solvente $\mathrm{CO}_{2}$ não linear, da mesma maneira foram feitas simulações clássicas e cálculos quânticos neste sistema molecular (descrevemos essa situação como caso 4). Este último procedimento nos permitiu concluir que parte importante do shift no espectro de absorção da pNA vem da mudança estrutural. Neste modelo obtivemos um shift de $0.26 \mathrm{eV}$, em boa concordância com o valor experimental que é de $0.35 \mathrm{eV}$.

Concluímos, ao testar todas essas situações, que o campo de força utilizando o $\mathrm{CO}_{2}$ não linear e a pNA com a geometria modificada descreve de forma satisfatória a alteração do espectro de absorção da pNA. É importante destacar que o efeito de geometria, dado pela simulação utilizando-se a geometria modificada da pNA, tem uma contribuição importante no shift do espectro de absorção da pNA, mais do que os outros fatores como a linearidade do $\mathrm{CO}_{2}$ e a alteração de cargas (contribuição eletrostática). Por considerar apenas simulações clássicas e cálculos quânticos em determinada parte do sistema (metodologia S-QM/MM), este campo de força poderia ser utilizado em determinadas situações. Como resultados obtidos em um trabalho anterior [12] indicavam a inviabilidade de alguns campos de força por não reproduzirem o que se chama de $\mathrm{CO}_{2}$-filicidade, ou seja, a capacidade da pNA de atrair $\mathrm{CO}_{2}$ através de uma interação intermolecular não convencional [13], nosso objetivo consistiu em verificar alternativas para um campo de força deste sistema $\mathrm{pNA}+\mathrm{CO}_{2}$ supercrítico, onde utilizando-se a metodologia S-QM/MM, pudéssemos obter resultados em con- 
cordância com os dados experimentais já existentes, sem que ocorra a necessidade de usar uma dinâmica molecular de Born-Oppenheimer.

Um possível perspectiva seria testar esses modelos de campos de força em outras propriedades moleculares como, por exemplo, a blindagem magnética obtida em medidas de Ressonância Magnética Nuclear. 


\section{Referências Bibliográficas}

[1] S. Canuto, Editor Special edition of the Advances in Quantum Chemistry, "Combining Quantum Mechanics and Molecular Mechanics". Some Recent Progresses in QM/MM Methods, vol.59, 2010.

[2] M.P. Allen D.J. Tildesley, Computer Simulation of Liquids, Oxford University Press, 1987.

[3] A. Warshell and M. Levitt, J. Mol. Biol. 103, 227 (1976).

[4] S. Canuto, Editor, Solvation Effects on Molecules and Biomolecules. Computational Methods and Applications. Springer (2008).

[5] B. J. C. Cabral, R. Rivelino, K. Coutinho and S. Canuto, J. Chem. Phys. 142, 024504 (2015).

[6] Y. Guissani and B. Guillot, J. Chem. Phys. 98, 8221 (1993).

[7] H. Oka and O. Kajimoto, Phys. Chem. Chem. Phys. 5, 2535 (2003).

[8] C. S. Pomelli and J. Tomasi, J. Chem. Phys. A 101, 3561 (1997).

[9] D. G. Archer and P. Wang, J. Phys. Ref. Data 19, 371 (1990).

[10] M. Uematsu and E. U. Franck, J. Phys. Chem. Ref. Data 9, 1291 (1980).

[11] Z. Zhang and Z. Duan, J. Chem. Phys. 122, 214507 (2005). 
[12] M. Hidalgo, R. Rivelino and S. Canuto, J. Chem. Theory and Comput. 10, $1554(2014)$.

[13] R. Rivelino, J. Phys. Chem. A 112, 161 (2008); M. Altarsha, F. Ingrosso and M. F. Ruiz-Lopez, ChemPhysChem 13, 3397 (2009).

[14] K. Coutinho, "Modelo Discreto de Solvente. Solvatocromismo no Espectro de Absorção Molecular", Tese de Doutorado - USP, 1997.

[15] C. Bistafa, "Efeito de Solvente no Espectro de Absorção da 5-Fluorouracil. Análise de Diferentes Procedimentos Teóricos", Dissertação de Mestrado USP, 2011.

[16] M. H. Cardenuto, "Propriedades eletrônicas de átomos e moléculas em fluidos supercríticos", Tese de Doutorado - USP, 2013.

[17] P. Suppam e N. Ghoneim, Solvatochromism, American Chemical Society (1997).

[18] O. Tapia O. Goscinski, "Self-Consistent reaction field theory of solvent effects", Molecular Physics, vol. 29, 1975, pp.1653-1661.

[19] J. Tomasi e M. Persico, Chem. Rev. 94, 2027 (1994).

[20] J. Tomasi, "Thirty years of continuum solvation chemistry: a review, and prospects for the near future", Theoretical Chemistry Accounts, vol. 112, 2004,pp. 184-203.

[21] S. Miertus, E. Scrocco, J. Tomasi, Chem. Phys. 55, 117, (1981).

[22] J. Tomasi, B. Mennucci et al, Chem. Rev. 105, 2999 (2005).

[23] H. Senn and W. Thiel, Top. Curr. Chem. 268, 173 (2007). 
[24] H. Lin and D. Truhlar, Theo. Chem. Acc 117, 185 (2007).

[25] S. Canuto K. Coutinho, "From Hydrogen Bond to Bulk: Solvation Analysis of the $n-\pi^{*}$ Transition of Formaldehyde in Water", International Journal of Quantum Chemistry, vol. 77, 2000, pp. 192-198.

[26] K. Coutinho S. Canuto, "Solvent effects in emission spectroscopy: A Monte Carlo quantum mechanics study of the $n-\pi^{*}$ shift of formaldehyde in water", Journal of Chemical Physics, vol. 113, 2000, pp. 9132-9139.

[27] K. Coutinho and S. Canuto, DICE (version 2.9) "A general Monte Carlo program for Liquid Simulation", Universidade de São Paulo (2009).

[28] K. Coutinho, H.C. Georg, T.L. Fonseca, V. Ludwig and S. Canuto, Chemical Physics Letters 437, 148-152 (2007).

[29] N. Metropolis, A. W. Rosenbluth, M. N. Rosenb, A. H. Teller and E. Teller, J. Chem. Phys. 21, 1087 (1953).

[30] Maitland, G. C. and E. B. Smith; Mol. Phys., 22, 861 (1971).

[31] J. L. Yarnell, M. J. Katz and R. G. Wenzel, Phys. Rev. A 7 , 2130 (1973).

[32] A. Eisenstein and N. S. Gingrichi, Phys. Rev. 58 , 307 (1940).

[33] A. Eisenstein and N. S. Gingrichi, Phys. Rev. 62, 261 (1942).

[34] Szabo, A. e N. S. Ostlund, Modern Quantum Chemistry: Introduction to Advanced Eletronic Struture Theory, Dover Publ., New York (1996).

[35] J.D.M. Vianna, A. Fazzio, S. Canuto, Teoria Quântica de Moléculas e Sólidos, São Paulo: Editora Livraria da Física, 2004. 
[36] N.H. Morgon K. Coutinho, eds., Métodos de Química Teórica e Modelagem Molecular, São Paulo: Editora Livraria da Física, 2007.

[37] J. A. Pople and D. L. Beveridge, Aproximate Molecular Orbital Theory, McGraw-Hill (1970).

[38] I. N. Levine, Quantum Chemistry, Prentice Hall, Upper saddle river, NJ (2009).

[39] J. J. Sakurai, Modern Quantum Mechanics, Massachusetts: Addison-Wesley Publishing Company, 1994.

[40] D. J. Griffiths, Introduction to Quantum Mechanics, London: Pearson Prentice Hall, 2005.

[41] C. Møller e M. S. Plesset, Phys. Rev. 46, 618 (1934).

[42] P. Hohenberg e W. Kohn, Phys. Rev. 136, B864 (1964).

[43] R.G. Parr W. Yang, Density-Functional Theory of Atoms and Molecules, New York: Oxford Science Publications, 1989.

[44] A.D. Becke, Phys. Rev. A 38, 3098-3100 (1988).

[45] A. D. Becke, J. Chem. Phys. 98, 5648 (1993).

[46] J. P. Perdew, Phys. Rev. B 33, 8822 (1986).

[47] C. Lee, W. Yang and R. G. Parr, Phys. Rev. B, 37, 785 (1998).

[48] C. Lee, W. Yang and R.G. Parr, Physical Review B 37, 785-789 (1988).

[49] S.H. Vosko, L. Wilk and M. Nusai, Canadian Journal of Physics 58, 1200-1211 (1980). 
[50] M.E. Casida, in: D.P. Chong (Ed.), Recent Advances in Density Functional Methods, vol. 1, World Scientific, Singapore, 1995.

[51] R. Bauernschmitt, R. Ahlrichs, Chem. Phys. Lett. 256, 454 (1996).

[52] D.J. Tozer and N.C. Handy, J. Chem. Phys. 109, 10180 (1998).

[53] D.J. Tozer, R.D. Amos, N.C. Handy, B.O. Roos and L. Serrano-Andres, Mol. Phys. 97, 859 (1999).

[54] A. Dreuw, J.L. Weisman and M. Head-Gordon, J. Chem. Phys. 119, 2943 (2003).

[55] L. Bernasconi, M. Sprik and J. Hutter, J. Chem. Phys. 119, 12417 (2003).

[56] T. Yanai, D. P. Tew and N. C. Handy, Chem. Phys. Lett. 393, 51-57 (2004).

[57] Y. Tawada, T. Tsuneda, S. Yanagisawa, T. Yanai, and K. Hirao, J. Chem. Phys. 120, 8425-8433 (2004).

[58] K. Andersson, P.-A. Malmqvist, B.O. Roos, A.J. Sadlej and K. Wolinski, J. Phys. Chem. 94, 5483 (1990).

[59] P. Raveendran, Y. Ikushima, and S.L. Wallen, Acc. Chem. Res. 38, 478-485 (2005).

[60] S. G Kazarian, M. F. Vincent, F. V. Bright, C. L. Liotta and C. A. Eckert, J. Am. Chem. Soc. 118, 1729-1736 (1996).

[61] C. Reichardt, Solvents and Solvent Effects in Organic Chemistry, 4th Ed. Wiley-VCH (2010).

[62] P. Jessop and W. Leitner, Handbook of Green Chemistry, Volume 4: Supercritical Solvents. W. Leitner and W. Jessop (Eds.) Wiley-VCH, 1-30 (2010). 
[63] J. M. DeSimone, Z. Guan and C. S. Elsbernd, Science 267, 945-947 (1992).

[64] G. H. Brunner (Ed.), Supercritical Fluids as Solvents and Reaction Media. Elsevier (2004).

[65] E. J. Beckman, J. of. Supercritical Fluids 28, 121 (2004).

[66] O. Kajimoto, Chem. Rev. 99, 355 (1999).

[67] S. Tuker, Chem. Rev. 99, 391 (1999).

[68] B. Subramaniam, R. A. Rajewski and K. Snavely, J. Pharm. Sci. 86, 885-890 (1997).

[69] L. Reynolds, J. A. Gardecki, S. J. V. Frankland, M. L. Horng and M. Maroncelli, J. Phys. Chem. 100, 10337-10354 (1996).

[70] J. F. Kauffman, J. Phys. Chem. A 105, 3433-3442 (2001).

[71] A. Wesch, N. Dahmen and K. H. Ebert, Ber. Bunsenges Phys. Chem. 100, 1368 (1996).

[72] B. J. C. Cabral, R. Rivelino, K. Coutinho and S. Canuto, J. Phys. Chem. B 119, 8397-8405 (2015).

[73] H. C. Georg, K. Coutinho and S. Canuto, J. Chem. Phys. 126, 34507 (2007).

[74] M. J. Frisch, G. W. Trucks, H. B. Schlegel, G. E. Scuseria, M. A. Robb, J. R. Cheeseman, G. Scalmani, V. Barone, B. Mennucci, G. A. Petersson, H. Nakatsuji, M. Caricato, X. Li, H. P. Hratchian, A. F. Izmaylov, J. Bloino, G. Zheng, J. L. Sonnenberg, M. Hada, M. Ehara, K. Toyota, R. Fukuda, J. Hasegawa, M. Ishida, T. Nakajima, Y. Honda, O. Kitao, H. Nakai, T. Vreven, J. A. Montgomery, Jr., J. E. Peralta, F. Ogliaro, M. Bearpark, J. J. 
Heyd, E. Brothers, K. N. Kudin, V. N. Staroverov, T. Keith, R. Kobayashi, J. Normand,K. Raghavachari, A. Rendell, J. C. Burant, S. S. Iyengar, J. Tomasi, M. Cossi, N. Rega, J. M. Millam, M. Klene, J. E. Knox, J. B. Cross, V. Bakken, C. Adamo, J. Jaramillo, R. Gomperts, R. E. Stratmann, O. Yazyev, A. J. Austin, R. Cammi, C. Pomelli, J. W. Ochterski, R. L. Martin, K. Morokuma, V. G. Zakrzewski, G. A. Voth, P. Salvador, J. J. Dannenberg, S. Dapprich, A. D. Daniels, O. Farkas, J. B. Foresman, J. V. Ortiz, J. Cioslowski, and D. J. Fox, Gaussian, Inc., Wallingford CT, 2013.

[75] Y. Marcus, J. Phys. Org. Chem. 18, 373 (2005).

[76] S. Kim and K. P. Johnston, Ind. Eng. Chem. Res. 26, 1206 (1987).

[77] J. Hyatt, J. Org. Chem. 49, 5097 (1984).

[78] V. M. Farztdinov, R. Schanz, S. A. Kovalenko and N. P. Ernsting, J. Phys. Chem. A 104, 11486 (2000).

[79] C. L. Thomsen, J. Thøgersen and S. R. Keiding, J. Chem. Phys. A 102, 1062 (1998).

[80] S. A Kovalenko, R. Schanz, V. M. Farztdinov, H. Hennig and N. P. Ernsting, Chem. Phys. Lett. 323, 312 (2000)

[81] D. Truhlar, K. Anderson, S. Mielke, and J. Siepmann, J. Phys. Chem. A 113 (10), 2053-2059 (2009).

[82] W. L. Jorgensen, D. S. Maxwell and Tirado-Rives, J. Am. Chem. Soc. 118, 11225 (1996).

[83] H. Reis, M. G. Papadopoulos and A. Gryzbowski, J. Phys. Chem. B 110, 18537 (2006). 
[84] S. Millefiori, G. Favini, A. Millefiori and D. Grasso, Spectrochim. Acta A 33, 21-27 (1977)

[85] M. E. Sigman, S. M. Lindley and J. E. Leffler, J. Am. Chem. Soc. 107, 1471 (1985).

[86] H.C. Georg, "Efeitos do Meio em Propriedades Conformacionais e Eletrônicas de Moléculas", Tese de Doutorado - USP, 2006. 